Review

\title{
Twenty-Five Years of Structural Parvovirology
}

\author{
Mario Mietzsch ${ }^{\dagger}$, Judit J. Pénzes ${ }^{\dagger}$ and Mavis Agbandje-McKenna * \\ Department of Biochemistry and Molecular Biology, Center for Structural Biology, The McKnight Brain Institute, \\ University of Florida, Gainesville, FL 32610, USA; mario.mietzsch@ufl.edu (M.M.); judit.penzes@ufl.edu (J.J.P.) \\ * Correspondence: mckenna@ufl.edu; Tel.: +1-352-294-8393 \\ + These authors contributed equally to this work.
}

Received: 19 March 2019; Accepted: 11 April 2019; Published: 20 April 2019

\begin{abstract}
Parvoviruses, infecting vertebrates and invertebrates, are a family of single-stranded DNA viruses with small, non-enveloped capsids with $\mathrm{T}=1$ icosahedral symmetry. A quarter of a century after the first parvovirus capsid structure was published, approximately 100 additional structures have been analyzed. This first structure was that of Canine Parvovirus, and it initiated the practice of structure-to-function correlation for the family. Despite high diversity in the capsid viral protein (VP) sequence, the structural topologies of all parvoviral capsids are conserved. However, surface loops inserted between the core secondary structure elements vary in conformation that enables the assembly of unique capsid surface morphologies within individual genera. These variations enable each virus to establish host niches by allowing host receptor attachment, specific tissue tropism, and antigenic diversity. This review focuses on the diversity among the parvoviruses with respect to the transcriptional strategy of the encoded VPs, the advances in capsid structure-function annotation, and therapeutic developments facilitated by the available structures.
\end{abstract}

Keywords: parvovirus; densovirus; single stranded DNA virus; X-ray crystallography; Cryo-EM; antibody interactions; receptor interactions

\section{Introduction}

The Parvoviridae are linear, single-stranded DNA packaging viruses with genomes of $\sim 4$ to $6 \mathrm{~kb}$. They have a large host spectrum, spanning members of the phylum Cnidaria to amniote vertebrates. Currently the Parvoviridae is divided into two subfamilies based on their ability to infect either vertebrates or invertebrates [1]. Viruses infecting vertebrate and invertebrate hosts are assigned to Parvovirinae and Densovirinae subfamilies, respectively, although the monophyly of the latter is questioned due to the diversity of members, and new emerging vertebrate viruses close to the Densovirinae may require a new subfamily (Figure 1). 


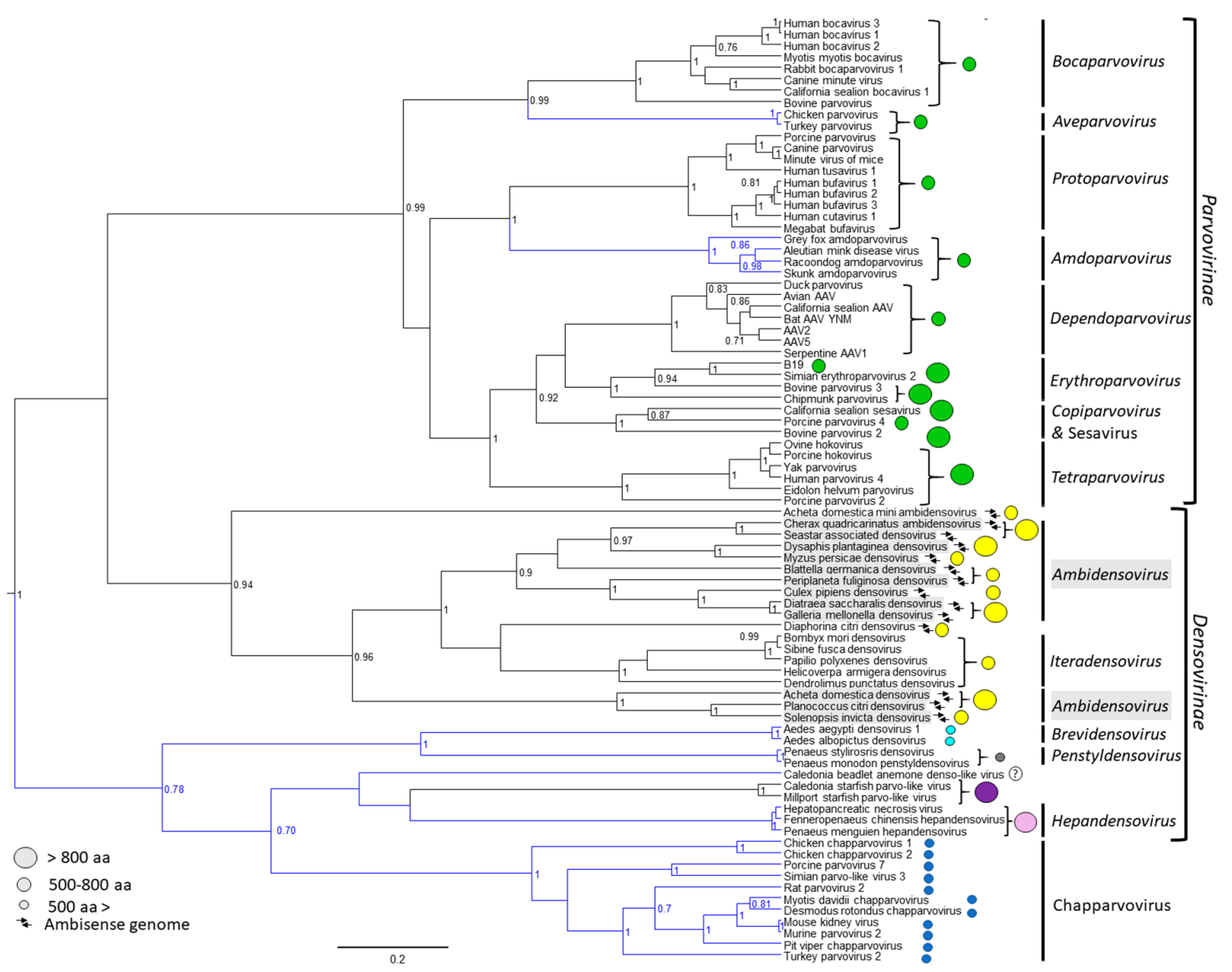

Figure 1. Evolutionary relationships of members of family Parvoviridae based on the conserved NS1 tripartite helicase domain. Branches of lineages highlighted in blue indicate the absence of a phospholipase $\mathrm{A}_{2}\left(\mathrm{PLA}_{2}\right)$ domain in the minor capsid viral protein, VP1. Capsid protein encoding gene homology is mapped as circles of different colors, where same colored circles indicate homologous genes (homology search defined, without the incorporation of the $\mathrm{PLA}_{2}$ sequence, as whether a protein sequence gives a hit out of targeted 5000 sequences at an expectation value of 100 by the BlastP algorithm of the NCBI Blast application [2]). The size of the circle indicates the size of VP1 based on the scale to the left.

Parvovirus virions possess small non-enveloped capsids with a diameter of 200 to $280 \AA$ [3-9]. Their $\mathrm{T}=1$ icosahedral capsids are assembled from 60 viral proteins (VPs) encoded from the right-hand side open reading frame (ORF) (Figures 2 and 3). This ORF, also known as cap, encodes up to four different VPs, depending on genus, of varying length, which all share a common C-terminal region [1]. Generally, the smallest VP, which comprises the common C-terminal region, is expressed at a higher rate compared to the larger VP forms and is, therefore, considered the major VP. The larger, less abundant VPs are N-terminal extended forms that contain regions important for the viral life cycle. Among these are a phospholipase $\mathrm{A}_{2}\left(\mathrm{PLA}_{2}\right)$ domain, a calcium-binding domain, and nuclear localization signals that are highly conserved in some genera [10-13]. The larger VPs are also incorporated into the capsid, albeit at low copy number, with the common C-terminus responsible for assembling the parvoviral capsid. In the different parvoviruses, the shared VP region varies between $\sim 40$ to $70 \mathrm{kDa}$ in size (Figures 2 and 3). This review focuses on the transcription mechanism, and the sequenceand structure-based homology of the parvovirus VPs, as well as the characteristic features of the parvoviral capsids. We also discuss structure-function annotation and the use of structure to guide the development of gene delivery vectors. 


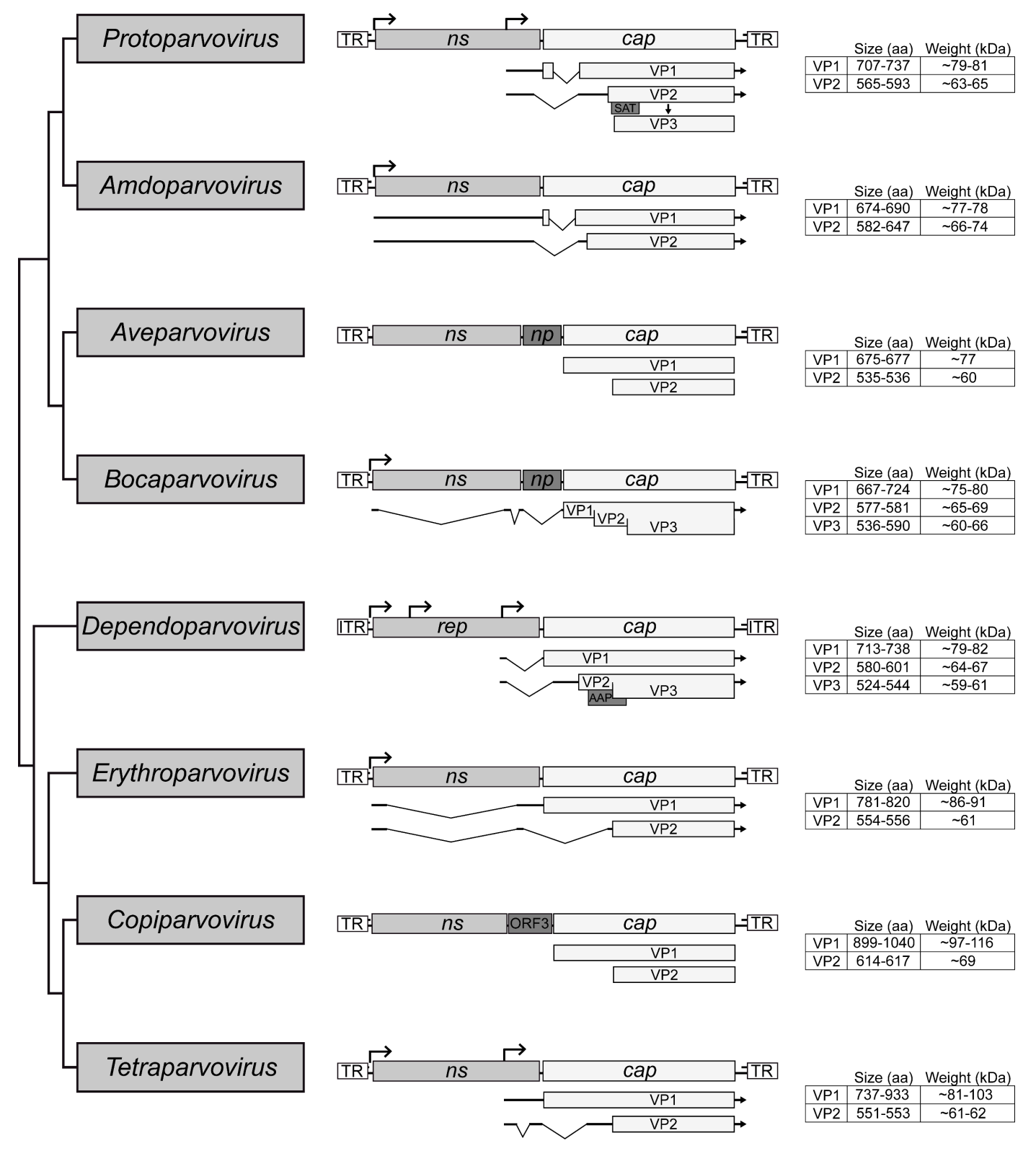

Figure 2. Cladogram of the subfamily Parvovirinae. The eight genera are shown. The general genome organization of each genus is shown in the middle with their ORF. The non-structural (NS) protein expressing genes $n s$ or rep are simplified and only the ORF is shown. Below the cap ORF the transcripts for the expression of the individual VP are shown. On the right side the size and weight of the VPs are given. Note that the transcription profiles of the Aveparvovirus and Copiparvovirus genera have not been determined, and thus the sizes of the VPs are based on in silico predictions. 




Figure 3. Cladogram of denso- and chapparvoviruses. The general genome organization and capsid protein expression strategy are shown. The $n s$ genes are simplified and only the ORF is shown. The transcription strategy of members of genus Hepandensovirus, as well as of the new, unclassified starfish densoviruses, have not been determined, thus the sizes of the VPs are based on in silico predictions.

\section{Parvovirinae}

The Parvovirinae is subdivided into eight genera: Amdoparvovirus, Aveparvovirus, Bocaparvovirus, Dependoparvovirus, Erythroparvovirus, Copiparvovirus, Protoparvovirus, and Tetraparvovirus (Figures 1 and 2) [1]. As the genus name suggests, the dependoparvoviruses require helper virus functions for replication [14-18]. All other genera contain members capable of autonomous replication. The Parvovirinae viral genomes contain two or three ORFs (Figure 2). The left ORF, the ns or rep gene, encodes a series of regulatory proteins that are indispensable for viral replication. Due to its higher level of conservation, this gene is used for the classification of parvoviruses into different genera (Figure 1). The right ORF, the cap gene, encodes up to three VPs that assemble the capsid (Figure 2) [1]. In addition, multiple genera express smaller regulatory proteins, such as nucleoprotein 1 (NP1) by the Aveparvovirus and Bocaparvovirus encoded near the middle of their genome, or the assembly activating 
protein (AAP) by the Dependoparvovirus, and the small alternatively translated (SAT) and non-structural protein 2 (NS2) by the Protoparvovirus, encoded within alternative reading frames of the main ORFs.

\subsection{Expression of the Parvovirinae VPs Utilizes Different Transcription Strategies}

The VPs of the Parvovirinae are encoded in the same orientation as the $n s$ or rep gene. Members of the Amdoparvovirus, Bocaparvovirus, and Erythroparvovirus use the same promoter for the expression of the NSs and VPs (Figure 2). The Dependoparvovirus, Protoparvovirus, and Tetraparvovirus utilize an additional promoter located at the $3^{\prime}$ end of the ns/rep gene for the expression of the cap ORF $[19,20]$. The transcription profiles for Aveparvovirus and Copiparvovirus are unknown. For the expression of the different VPs, most Parvovirinae members perform alternative splicing of their transcripts or utilize alternative start codons (Figure 2) [19-25]. Differences in splicing efficiency and leaky scanning during translation initiation, as well as the utilization of non-canonical start codons, result in the higher expression of the smallest VP form over the larger N-terminal extended forms (Figure 2) [20-25]. The translated VPs are translocated to the nucleus, where they assemble into the 60 mer capsid [26,27]. Based on their expression levels, the minor and major capsid VPs are reported to be incorporated at ratios of 1:10 for VP1:VP2 in capsids containing two VPs, for example, human parvovirus B19, and 1:1:10 for VP1:VP2:VP3 in capsids with three VPs, such as the Adeno-associated viruses (AAVs) [28-31]. For some Parvovirinae members this process is assisted by additional proteins, such as the AAP of the dependoparvoviruses or NS2 of the protoparvoviruses [27,32]. The viral genome is reportedly translocated into pre-assembled empty capsids utilizing the helicase function of NS/Rep proteins [33]. For some protoparvoviruses, proteolytic cleavage of VP2 following DNA packaging removes $\sim 20$ to 25 amino acids from the N-terminus to create VP3 (Figure 2) [34-37].

\subsection{Parvovirinae Genera Display Distinct Capsid Surface Morphologies}

The first structure of a parvovirus, that of wild type (wt) canine parvovirus (CPV), a member of Protoparvovirus, was published in 1991, with the VP structure coordinates deposited in 1993, a quarter of a century ago [6,38]. Since then numerous other capsid structures, $>100$, have been determined for the protoparvoviruses, as well as members of three other (of the eight) Parvovirinae genera, including complexes with receptors or antibodies (Table 1, Section 2.5, and Section 2.6). The structures of capsids alone include those of wt as well as variants. The studies have primarily utilized X-ray crystallography, and in recent years increasingly cryo-electron microscopy and 3-dimensional image reconstruction (cryo-EM) as the method began to generate atomic resolution structures. The most capsid (no ligand) structures determined have been for the dependoparvoviruses and protoparvoviruses, for which more than 20 structures are available, followed by four for the bocaparvoviruses, and one for Erythroparvovirus (Table 1). 
Table 1. Summary of deposited Parvovirinae capsid structures.

\begin{tabular}{|c|c|c|c|c|c|c|}
\hline Virus & Empty/Full & $\begin{array}{c}\text { Structure Determination } \\
\text { Method }\end{array}$ & Year & Resolution in $\AA$ & PDB-ID & Reference \\
\hline \multicolumn{7}{|c|}{ Protoparvovirus } \\
\hline $\mathrm{BuV1}$ & Empty & Cryo-EM & 2018 & 2.8 & $6 \mathrm{BWX}$ & Ilyas et al. [39] \\
\hline $\mathrm{BuV} 2$ & Empty & Cryo-EM & 2018 & 3.8 & $6 \mathrm{~B} \times 0$ & Ilyas et al. [39] \\
\hline $\mathrm{BuV3}$ & Empty & Cryo-EM & 2018 & 3.3 & $6 \mathrm{BX} 1$ & Ilyas et al. [39] \\
\hline $\mathrm{CPV}$ & Empty & X-Ray Crystallography & 1993 & 3.0 & 2CAS & Wu et al. [38] \\
\hline CPV & Full & X-Ray Crystallography & 1996 & 2.9 & $4 \mathrm{DPV}$ & Xie et al. [40] \\
\hline CPV-N93D & Full & X-Ray Crystallography & 2003 & 3.3 & $1 \mathrm{P} 5 \mathrm{Y}$ & Govindasamy et al. [41] \\
\hline CPV-N93R & Full & X-Ray Crystallography & 2003 & 3.3 & $1 \mathrm{P} 5 \mathrm{~W}$ & Govindasamy et al. [41] \\
\hline CPV-d-A300D & Empty & X-Ray Crystallography & 2000 & 3.3 & $1 \mathrm{C} 8 \mathrm{D}$ & Simpson et al. [42] \\
\hline CPV-d-A300D & Full & X-Ray Crystallography & 1996 & 3.3 & 1IJS & Llamas-Saiz et al. [43] \\
\hline CPV-d pH5.5 & Empty & X-Ray Crystallography & 2000 & 3.5 & $1 \mathrm{C} 8 \mathrm{H}$ & Simpson et al. [42] \\
\hline CPV2a & Full & X-Ray Crystallography & 2014 & 3.3 & 4QYK & Organtini et al. [44] \\
\hline FPV & Empty & X-Ray Crystallography & 1993 & 3.3 & $1 \mathrm{FPV}$ & Agbandje et al. [45] \\
\hline FPV & Empty & X-Ray Crystallography & 2000 & 3.0 & $1 \mathrm{C} 8 \mathrm{~F}$ & Simpson et al. [42] \\
\hline FPV low $\mathrm{pH}$ & Empty & X-Ray Crystallography & 2000 & 3.0 & $1 \mathrm{C} 8 \mathrm{G}$ & Simpson et al. [42] \\
\hline FPV no $\mathrm{CaCl}_{2}$ & Empty & X-Ray Crystallography & 2000 & 3.0 & $1 \mathrm{C} 8 \mathrm{E}$ & Simpson et al. [42] \\
\hline H-1PV & Full & X-Ray Crystallography & 2013 & 2.7 & $4 \mathrm{G} 0 \mathrm{R}$ & Halder et al. [46] \\
\hline $\mathrm{H}-1 \mathrm{PV}$ & Empty & X-Ray Crystallography & 2013 & 3.2 & $4 \mathrm{GBT}$ & Halder et al. [46] \\
\hline LuIII & Empty & Cryo-EM & 2017 & 3.2 & $6 \mathrm{~B} 9 \mathrm{Q}$ & Pittman et al. [47] \\
\hline M. Spretus EVE & Empty & Cryo-EM & 2018 & 3.9 & $6 \mathrm{NF9}$ & Callaway et al. [48] \\
\hline MVMi & Full & X-Ray Crystallography & 1997 & 3.5 & 1MVM & Llamas-Saiz et al. [49] \\
\hline MVMi & Empty & X-Ray Crystallography & 2005 & 3.5 & $1 \mathrm{Z1C}$ & Kontou et al. [50] \\
\hline MVMi-L172W & Empty & X-Ray Crystallography & 2011 & 4.2 & 2XGK & Plevka et al. [51] \\
\hline MVMp & Full & X-Rav Crystallography & 2005 & 3.3 & $1 \mathrm{Z} 14$ & Kontou et al. [50] \\
\hline MVMp-N170A & Empty & X-Ray Crystallography & 2015 & 3.8 & $4 Z P Y$ & Guerra et al. [52] \\
\hline PPV & Empty & X-Ray Crystallography & 2001 & 3.5 & $1 \mathrm{~K} 3 \mathrm{~V}$ & Simpson et al. [53] \\
\hline \multicolumn{7}{|c|}{ Bocaparvovirus } \\
\hline BPV & Empty & X-Ray Crystallography & 2015 & 3.2 & $4 Q C 8$ & Kailasan et al. [5] \\
\hline HBoV1 & Empty & Cryo-EM & 2017 & 2.9 & 5URF & Mietzsch et al. [54] \\
\hline HBoV3 & Empty & Cryo-EM & 2017 & 2.8 & 5US7 & Mietzsch et al. [54] \\
\hline HBoV4 & Empty & Cryo-EM & 2017 & 3.0 & 5US9 & Mietzsch et al. [54] \\
\hline
\end{tabular}


Table 1. Cont.

\begin{tabular}{|c|c|c|c|c|c|c|}
\hline Virus & Empty/Full & $\begin{array}{c}\text { Structure Determination } \\
\text { Method }\end{array}$ & Year & Resolution in $\AA$ & PDB-ID & Reference \\
\hline \multicolumn{7}{|c|}{ Dependoparvovirus } \\
\hline AAV1 & Full & X-Ray Crystallography & 2011 & 2.5 & 3NG9 & Ng et al. [55] \\
\hline AAV2 & Full & X-Ray Crystallography & 2002 & 3.0 & 1LP3 & Xie et al. [3] \\
\hline AAV2 & Empty & Cryo-EM & 2016 & 3.8 & 5IPI & Drouin et al. [56] \\
\hline AAV2-L336C & Empty & Cryo-EM & 2018 & 1.9 & $6 \mathrm{E} 9 \mathrm{D}$ & Tan et al. [57] \\
\hline AAV2-R432A & Empty & Cryo-EM & 2016 & 3.7 & 5IPK & Drouin et al. [56] \\
\hline AAV2.5 & Full & Cryo-EM & 2018 & 2.8 & $6 \mathrm{CBE}$ & Burg et al. [58] \\
\hline AAV3 & Full & X-Ray Crystallography & 2010 & 2.6 & $3 \mathrm{KIC}$ & Lerch et al. [59] \\
\hline AAV4 & Full & X-Ray Crystallography & 2007 & 3.2 & $2 \mathrm{G} 8 \mathrm{G}$ & Govindasamy et al. [60] \\
\hline AAV5 & Empty & X-Ray Crystallography & 2010 & 3.5 & 3NTT & Govindasamy et al. [61] \\
\hline AAV6 & Empty & X-Ray Crystallography & 2010 & 3.0 & 3ОAH & Ng et al. [55] \\
\hline AAV6 & Full & X-Ray Crystallography & 2011 & 3.0 & $4 \mathrm{~V} 86$ & Xie et al. [62] \\
\hline AAV8 & Empty & X-Ray Crystallography & 2007 & 2.6 & 2QA0 & Nam et al. [63] \\
\hline AAV8 pH7.5 & Full & X-Ray Crystallography & 2011 & 2.7 & 3RA4 & Nam et al. [64] \\
\hline AAV8 pH6.0 & Full & X-Ray Crystallography & 2011 & 2.7 & 3RA9 & Nam et al. [64] \\
\hline AAV8 pH5.5 & Full & X-Ray Crystallography & 2011 & 2.7 & 3RA8 & Nam et al. [64] \\
\hline AAV8 pH4.0 & Full & X-Ray Crystallography & 2011 & 2.7 & 3RA2 & Nam et al. [64] \\
\hline AAV8 pH4/7.5 & Full & X-Ray Crystallography & 2011 & 3.2 & 3RAA & Nam et al. [64] \\
\hline AAV9 & Empty & X-Ray Crystallography & 2011 & 2.8 & $3 \mathrm{UX1}$ & Dimattia et al. [65] \\
\hline AAV9-L001 & Full & Cryo-EM & 2019 & 3.2 & $6 \mathrm{NXE}$ & Guenther et al. [66] \\
\hline AAV-DJ & Empty & Cryo-EM & 2012 & 4.5 & $3 \mathrm{~J} 1 \mathrm{Q}$ & Lerch et al. [67] \\
\hline AAVrh. 8 & Full & X-Ray Crystallography & 2014 & 3.5 & 4RSO & Halder et al. [68] \\
\hline AAVrh.32.33 & Full & X-Ray Crystallography & 2013 & 3.5 & $4 \mathrm{IOV}$ & Mikals et al. [69] \\
\hline \multicolumn{7}{|c|}{ Erythroparvovirus } \\
\hline B19 & Empty & X-Ray Crystallography & 2004 & 3.5 & $1 \mathrm{~S} 58$ & Kaufmann et al. [4] \\
\hline
\end{tabular}


In all the structures, the N-terminal regions of the larger VP (e.g., VP1u), as well as the N-terminal 20-40 amino acids of the major VP, are not resolved. The N-termini of the larger VPs are believed to be located on the inside of the capsid and were shown not to affect the overall capsid structure [70]. The inability to determine the structure of these N-termini is likely due to their flexibility and their low copy numbers within the capsid. The exception to this was human parvovirus B19, for which low resolution cryo-EM maps showed density interpreted as the VP2 N-termini [71]. The flexibility resulting in the N-termini disorder arises from a glycine-rich N-terminal region present in most Parvovirinae (Figure 4). Furthermore, the low copy number of the minor VPs or a different positioning of the N-terminus of the different VPs is incompatible with the icosahedral averaging applied during structure determination. A disorder prediction indicates that the glycine-rich stretch is highly disordered in all analyzed Parvovirinae, while the VP1u and the overlapping C-terminal VP region are generally more ordered (Figure 5).

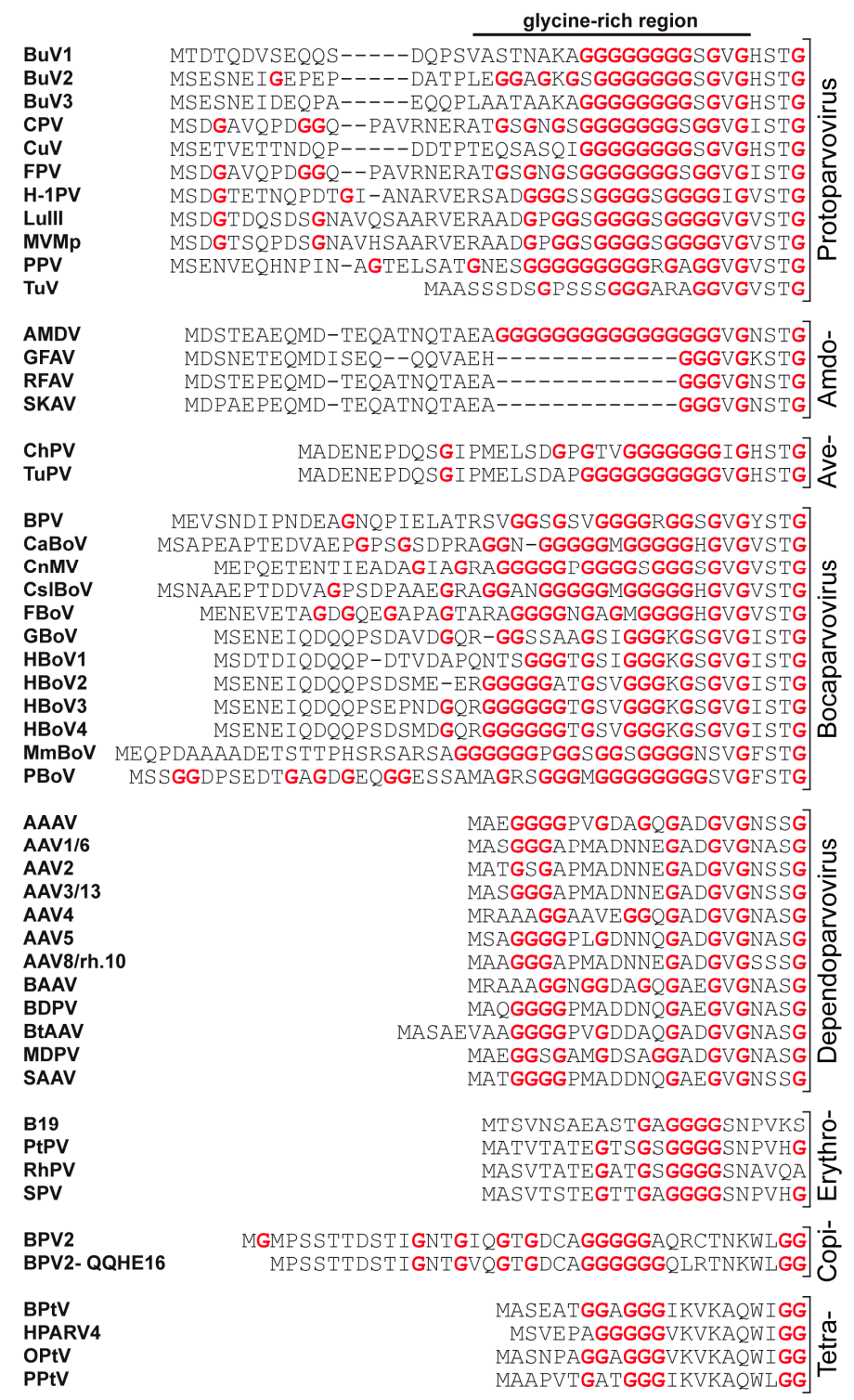

Figure 4. The N-termini of the major VPs of the Parvovirinae. For each genus a selection of available VP sequences are shown for the N-terminal 20-50 amino acids. All glycine residues are shown in red. 

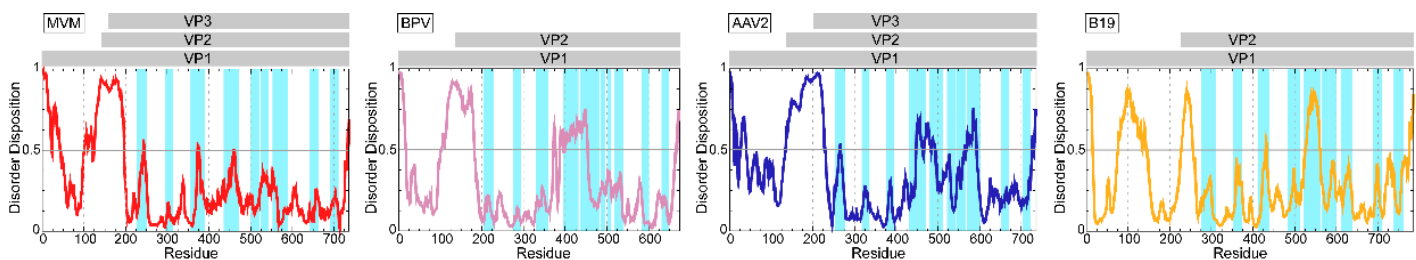

Figure 5. Disorder prediction for type members MVMp (red), BPV (pink), AAV2 (blue), and Parvovirus B19 (orange) VP1 by the PONDR_fit application [72]. Regions above 0.5 on the Y-axis are predicted to be disordered. Gray line drawings above the images indicate the approximate positions of the VPs. The regions highlighted in light blue indicate the locations of the surface exposed loops, the tops of which are defined as variable regions.

The cluster of glycines and associated flexibility likely serve to enable the externalization of VP1u for the $\mathrm{PLA}_{2}$ function contained within [10]. Consistently, in reported Parvovirinae structures, the first ordered $\mathrm{N}$-terminal residue of the overlapping VP region is located after the glycine-rich region, and inside the capsid under the only channel in the capsid. This channel, located at the icosahedral 5 -fold axis, connects the inside and outside of the capsid (see below) $[38,39,47,73,74]$. The remainder of the VP is ordered to the C-terminus in all Parvovirinae structures determined to date.

The CPV structure confirmed the icosahedral nature of the parvovirus capsids with sixty VPs assembling one capsid via 2-, 3-, and 5-fold symmetry related interactions [6,38,75]. The Parvovirinae VP structures display significant similarity despite low sequence identities (Table 2). The ordered VP monomer region consists of a core eight-stranded ( $\beta$ B to $\beta I$ ) anti-parallel $\beta$-barrel motif, also known as a jelly roll motif, with a BIDG sheet that forms the inner surface of the capsid (Figure 6) [76]. This $\beta$-barrel is conserved in all parvoviral capsid structures determined to date, as has been reported for many other viruses. In addition, a $\beta$ A strand that runs anti-parallel to the $\beta B$ strand of the BIDG sheet, and a conserved helix, $\alpha \mathrm{A}$, located between strands $\beta C$ and $\beta \mathrm{D}$, are also part of conserved Parvovirinae core structure (Figure 6). Loops inserted between the $\beta$-strands of the $\beta$-barrel form the surface of the capsid. These loops are named after the $\beta$-strands that they connect, for example, the $\mathrm{DE}$ loop connects the $\beta \mathrm{D}$ and $\beta \mathrm{E}$ strands. The $\mathrm{GH}$ loop that connects the $\beta \mathrm{G}$ and $\beta \mathrm{H}$ strands is the largest surface loop consisting of multiple sub-loops (Figure 6). The surface loops contain the highest amino acid sequence and structural diversity among members of the same genus and between different parvoviruses in general (Figure 7). Differences at the apexes of these loops are termed variable regions (VRs), defined as two or more amino acids with $\mathrm{C} \alpha$ positions greater than $1 \AA$ apart (for the dependoparvoviruses) [60] or $2 \AA$ apart (for the other Parvovirinae) [46] when their VPs are superposed. For the VPs of protoparvoviruses, bocaparvoviruses, and dependoparvoviruses nine to ten VRs have been defined (Figure 7).

Table 2. Sequence identity and structural similarity among Parvovirinae type members.

\begin{tabular}{|c|c|c|c|c|c|}
\hline & MVMp & BPV & AAV2 & B19 & \multirow{6}{*}{ 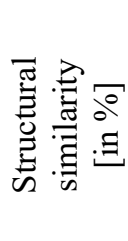 } \\
\hline MVMp & 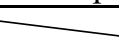 & 46.8 & 54.1 & 41.5 & \\
\hline BPV & 18.6 & & 61.4 & 49.9 & \\
\hline AAV2 & 17.4 & 22.9 & & 62.8 & \\
\hline \multirow[t]{2}{*}{ B19 } & 14.5 & 20.1 & 23.7 & & \\
\hline & & $\mathrm{P} 3 \mathrm{sec}$ & ity [in \% & & \\
\hline
\end{tabular}




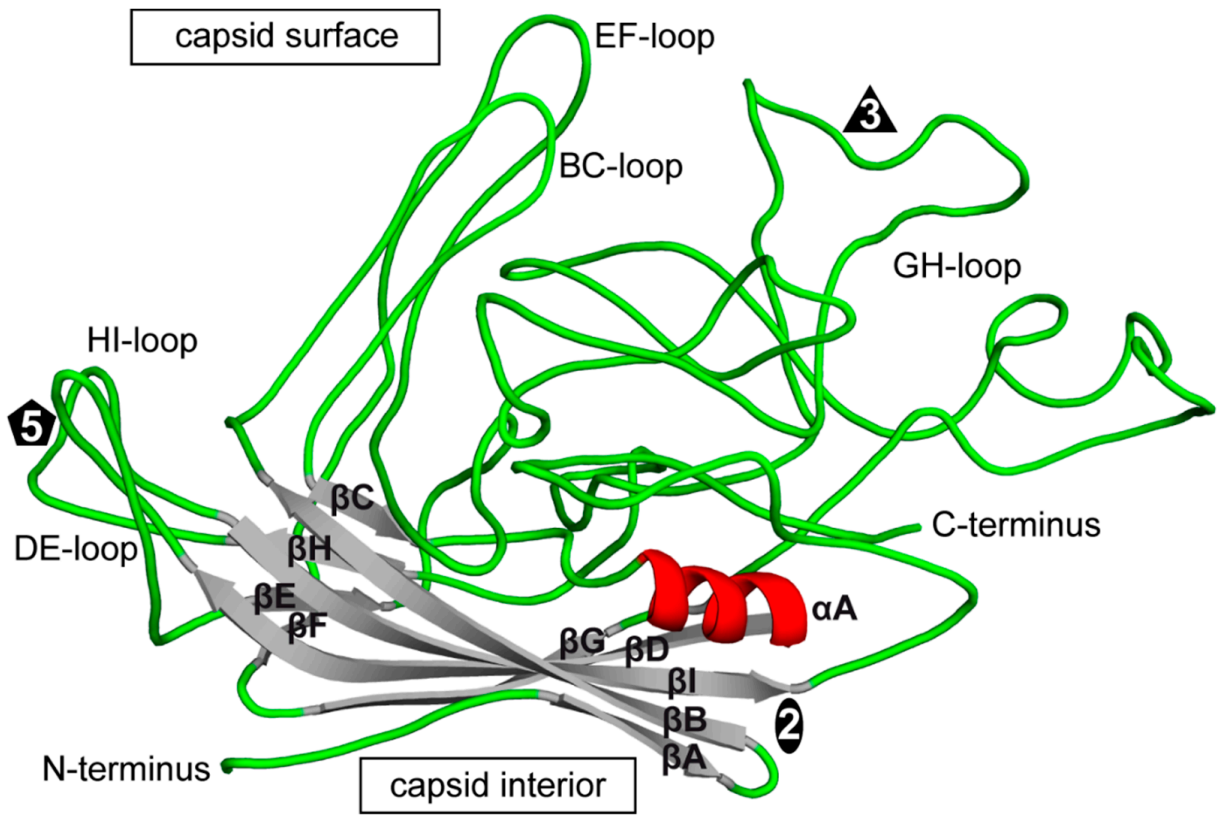

Figure 6. The structure of a VP monomer of CPV (PDB-ID: 2CAS). A cartoon ribbon diagram is shown. The beta strands ( $\beta$ A to $\beta I$, gray), $\alpha$-helix A (red), interconnecting surface loops (with all secondary structure elements removed, green), and the $\mathrm{N}$ - and $\mathrm{C}$-terminus are indicated. The approximate icosahedral 2-fold, 3-fold, and 5-fold axis are indicated by an oval, triangle, and pentagon, respectively. This image was generated using PyMOL [77].

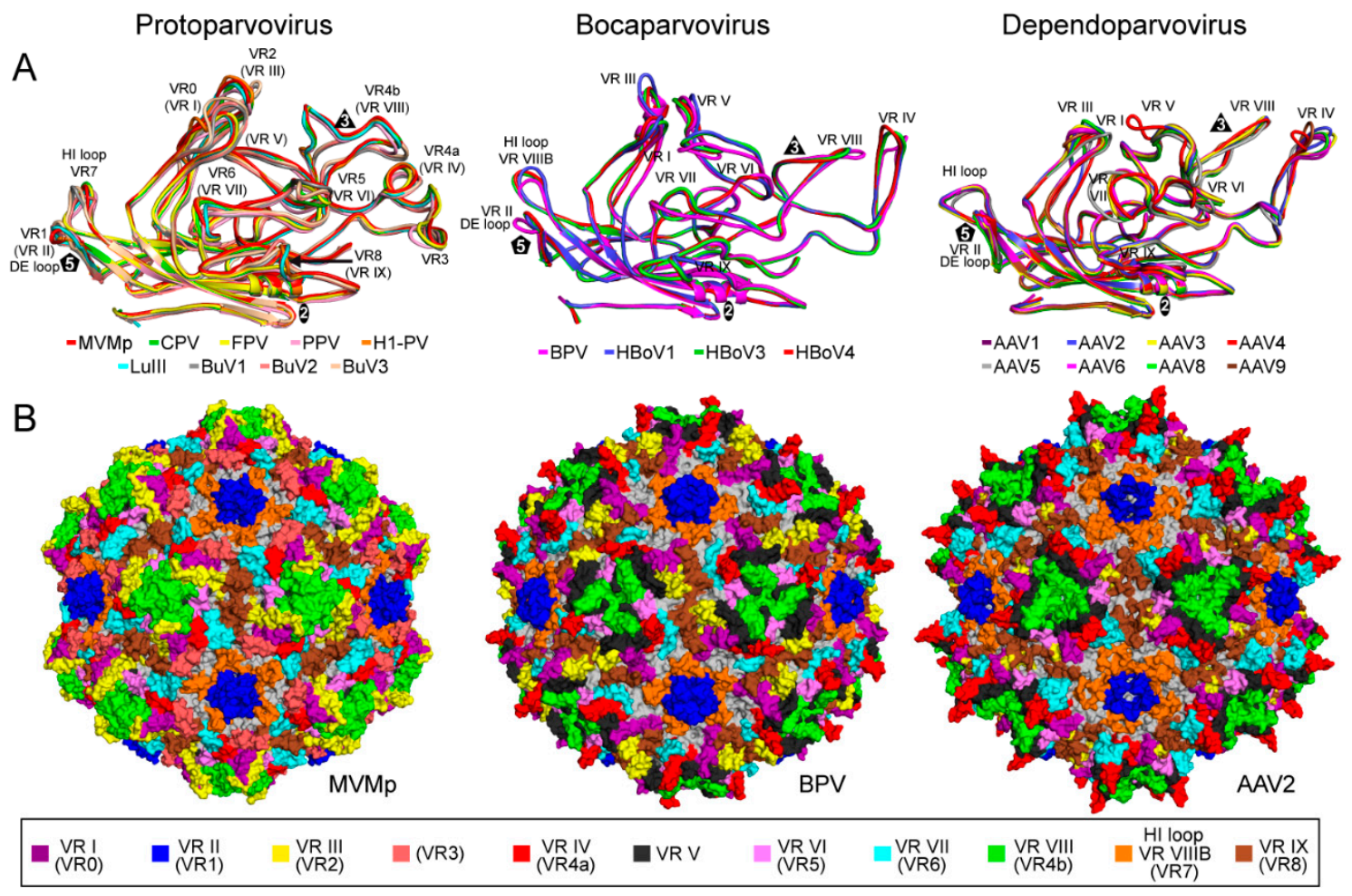

Figure 7. The VRs of the Parvovirinae. (A) Structural superposition of VP monomers from different members of Protoparvovirus (left), Bocaparvovirus (center), and Dependoparvovirus. Individual colors for the ribbons are as indicated. The VRs: VR-I to VR-IX (or VR0 to VR8 for the protoparvoviruses), the DE, and HI loops are shown. (B) Location of the VRs, colored as indicated, on the capsid surface of MVMp as an example for Protoparvovirus (left), BPV for Bocaparvovirus (center), and AAV2 for Dependoparvovirus (right). The figures were generated using PyMOL [77]. 
The locations of the VRs as well as the overall structure of the VP monomer within each genus and among the Parvovirinae are similar despite sequence identities as low as 15\% (Table 2, Figure 7). The different VR conformations create distinct genus level morphologies for the capsids, although the capsids have the same overall characteristic features (Figure 8). These include a channel at the icosahedral 5 -fold symmetry axes, assembled by five DE loops, surrounded by a depression, described as canyon-like, lined by the HI loop located above the neighboring VP's $\beta C H E F$ strands. The channel at the 5 -fold axes connects the interior of the capsid to the exterior and is believed to play an important role in most parvoviruses during the viral replication cycle by serving as the route of viral genome packaging, genome release, and the externalization of VP1u for its PLA 2 function [70,73]. Secondly, protrusions are located at or surrounding the icosahedral 3-fold axes assembled by loop/VR contributions from two or three VP monomers depending on genus (Figure 8). Variable regions IV, VR-V, and VR-VIII from two 3-fold related VP monomers contribute to the three separate protrusions of the dependoparvoviruses (Figures 7 and 8). Similarly, VR-IV, VR-V, and VR-VIII contribute to the 3-fold protrusions in the bocaparvoviruses, along with VR-I generating several dispersed peaks. In B19, two separate protrusions surround the icosahedral 3-fold axes (Figure 8). One of these protrusions is formed by VR-I and VR-III, the other by VR-VIII. However, the B19 structure lacks 13 residues within VR-V, which is located between both protrusions [4]. This region (aa 528-540, VP1 numbering) is predicted to be highly disordered (Figure 5) and could potentially merge both protrusions. In the animal protoparvoviruses, where the VRs are defined by Arabic numerals, VR0 (VR-I in the dependoparvoviruses), VR2 (VR-III), and VR4b (VR-VIII) form the single pinwheel 3-fold protrusions (Figures 7 and 8) [46,50,60]. In contrast, a deletion in VR4b near the 3-fold symmetry axis results in separated 3-fold protrusions for the bufaviruses (BuVs) (Figures 7 and 8) [39]. Within and among genera, the shape and size of the 3-fold protrusions vary because of sequence length and conformational loop differences. The variable surface loops at the 3-fold are reported to mediate the interactions of parvoviruses with different host factors, including receptors and antibodies (see Sections 2.6 and 2.7) [74]. Thirdly, a second depression is located at the 2 -fold symmetry axes of the capsid (Figure 8 ). The floor of the depression is lined by a conserved (within genus) stretch of residues C-terminus of the $\beta I$ strand. The shape of the depression, however, is variable in depth and width within and between genera (Figure 8) due to differences in side-chain orientations. The 2- and 5-fold depressions are separated by a raised capsid region, termed the 2-/5-fold wall, which displays structural variability among the Parvovirinae due to conformational differences in VR-VII and VR-IX. The 2-fold depression serves as a site for glycan receptor interaction for members of the protoparvoviruses, while the 2-/5-fold wall serves to bind receptors as well as antibodies for different genera (see Sections 2.6 and 2.7) [74].

Unique to the structure of bocaviruses is a "basket-like" feature underneath the 5-fold axis that extends the channel further into the interior of the capsid [5,54]. The basket arises from density located at the N-terminus of the observable VP structure and includes parts of the glycine-rich region [54]. This ordered density under the 5 -fold channel poses a problem with the proposed infection mechanism. The hypothesis is that at low $\mathrm{pH}$ conditions, similar to the environment in the late endosome, structural rearrangements of the basket occur that open up the 5-fold channel for VP1u externalization for its PLA 2 function. Interestingly, the structures of AAV8, CPV, and feline panleukopenia virus (FPV) determined at low $\mathrm{pH}$ conditions show structural changes at residues and capsid surface loops, although the 5-fold channel was not reported to be altered $[42,64]$. 


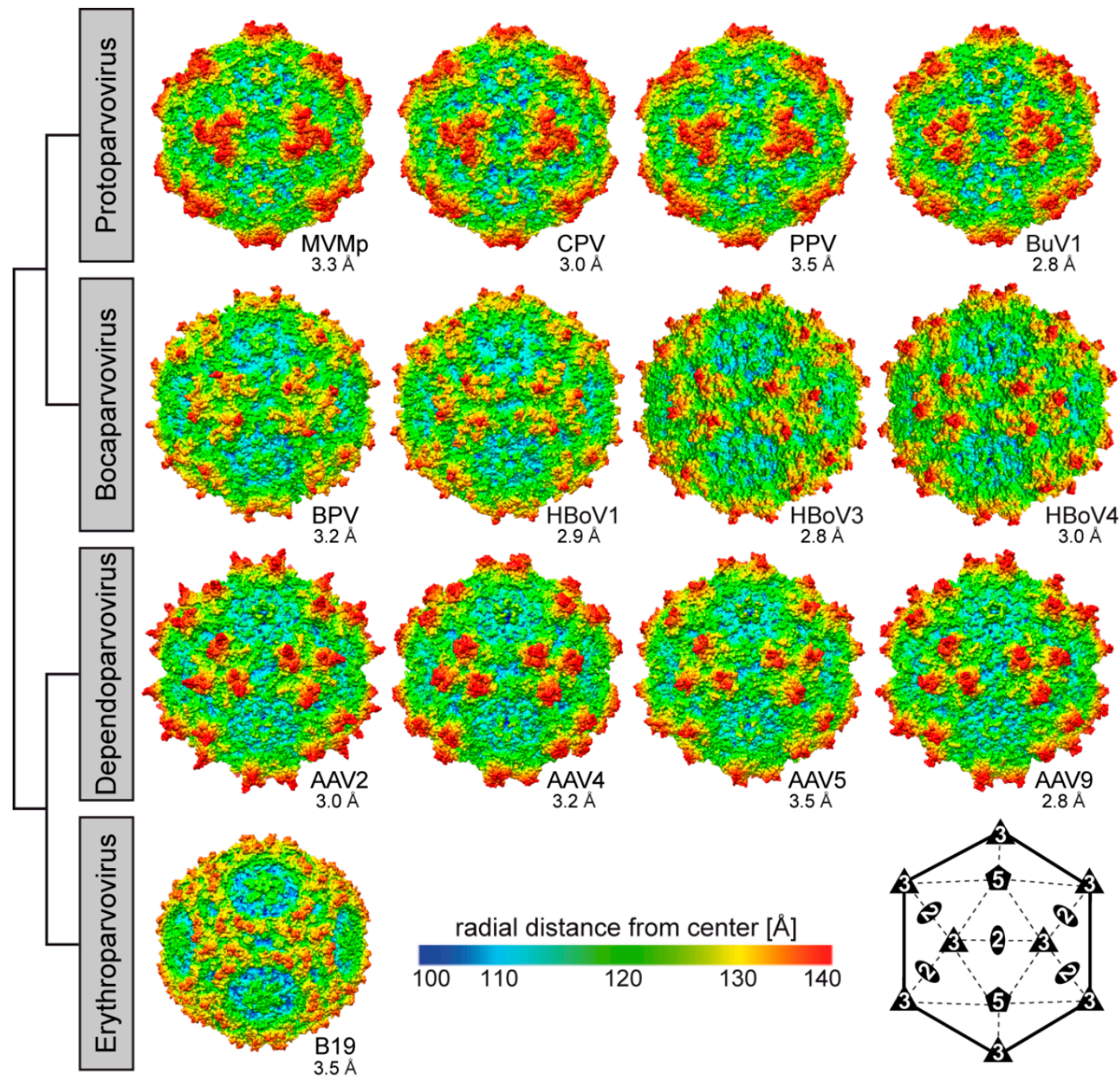

Figure 8. Capsid structures of the Parvovirinae subfamily. A selection of capsid structures is shown for Protoparvovirus, Bocaparvovirus, Dependoparvovirus, and Erythroparvovirus. The capsid surfaces are viewed down the icosahedral 2-fold axes and are colored according to radial distance from the particle center (blue to red), as indicated by the scale bar. The capsid images were generated using Chimera [78]. In the lower right hand side, a symmetry diagram illustrating the positions of the icosahedral symmetry axes on the capsid surfaces is shown.

\subsection{Nucleotides Are Ordered Inside Parvovirinae Capsids Despite Lack of Icosahedral Symmetry}

The ordering of nucleotides (nts) inside the capsids of some Parvovirinae is observed despite the lack of adherence of the single copy of the packaged genome or reporter gene to icosahedral symmetry. This has been observed for virus-like particles (VLPs) and DNA packaged (full) members of the dependoparvoviruses and full protoparvoviruses. A conserved pocket under the 3-fold symmetry axis shows the ordering of one or two nts for multiple AAV serotypes $[59,60,63,64,68,69]$. Low $\mathrm{pH}$ conditions reduced the ordered DNA density [64]. The loss of the nt density at $\mathrm{pH} 4.0$ suggested loss of capsid-DNA interaction that serves as one of the steps leading to release of the genome from the capsid following endosomal trafficking during infection [64]. The ordering of an nt in VLPs in absence of Rep protein suggests that capsid assembly may require nucleation by an $\mathrm{nt}$ for the dependoparvoviruses [63]. For the protoparvoviruses, large stretches of ordered DNA, $11 \mathrm{nt}$ in CPV [6], $19 \mathrm{nt}$ in minute virus of mice strain i (MVMi) [49,50], and $10 \mathrm{nt}$ in H-1PV [46], have been reported. The ordering of more nt compared to the dependoparvoviruses may be due to the packaging of only the negative sense genome in the protoparvoviruses, while the AAV packaging both polarities. The 
ordered protoparvoviruses nts are located within a pocket inside the capsid adjacent to the icosahedral 2 -fold axes in all the viruses. This was suggestive of a recognition motif, but a search through the wt genome of CPV identified matches only when 2-3 nt mismatches were allowed [79]. Thus, the role of this organized DNA beyond a common binding site in the Parvovirinae is yet to be determined.

\subsection{The Structure of Capsid Variants Provide Insight into Function}

As listed in Table 1, the structures of several variants have been determined for the Parvovirinae. The aims of these studies were structure-function understanding of observed biological phenotypes. The majority of variant structures studied are for AAV2, CPV, and MVM, which are among the best functionally characterized members of this subfamily. Currently, the highest resolution virus structure is that of an AAV2 variant with the leucine at position 336 (VP1 numbering) mutated to a cysteine, AAV2-L336C, at $1.9 \AA$, obtained by cryo-EM [57]. This mutant has a genome packaging defect and altered VP1u externalization properties [80]. A comparison of this structure to wt AAV2 identified a destabilization of the VP N-terminus inside the capsid and the widening of the base of the 5-fold channel in the variant [57]. This observation supports previous claims that the 5-fold region functions as a portal of genome packaging and VP1u externalization, and that the correct arrangement of the residues in the channel plays a crucial role in these functions. The structure of a similar variant with the equivalent leucine mutated to a tryptophan, was analyzed for MVM, MVM-L172W (VP2 numbering), by X-ray crystallography (Table 1) [51]. This variant was also reported to have a DNA packaging defect and altered VP1u externalization dynamics phenotype [81]. In the MVM-L172W structure, the tryptophan blocked the channel and also induced a reorganization of the N-terminus of VP2 [51]. This suggests that different perturbations in the same structural location can result in a similar inhibitory phenotype. A second AAV2 variant, AAV2-R432A, also characterized the determinant of another genome packaging defective virus resulting from a single residue change [82]. In the wt AAV2 structure, this residue is located within the capsid, neither on the inside nor the outside surface, and at the 3-fold axes. Its side-chain interacts with the main-chain of a surface loop [56]. The AAV2-R432A structure, also determined by cryo-EM, detailed the propagation of capsid destabilization to distant sites from R432, including the rearrangement of the $\beta$ A strand and movement of residue side-chains at the base of the 5-fold channel inside the capsid. The capsid was also less thermally stable than wt AAV2 [56]. Together, the data suggested that the structure rearrangements and destabilization resulted in packaging incompetence. The crystal structures of CPV variants, CPV-N93D, CPV-N93R, and CPV-A300D (VP2 numbering) in Table 1 were studied to understand the juxtaposition of amino acids controlling tissue tropism and antigenicity [41-43]. These residues form the footprint of the transferrin receptor and several antibody epitopes $[43,83,84]$. Furthermore, these studies showed that amino acid determinants could be localized far apart but function together $[41,85]$.

\subsection{Capsid-Receptor Complex Structures}

The role of the parvoviral capsid is to protect the packaged genome and to deliver it to the nucleus of the target cells for the next replication cycle. For the Parvovirinae, glycan receptors, for example terminal sialic acid (SIA), galactoses, heparan sulfate proteoglycans, P-antigen, and various proteins, including AAVR, transferrin, laminin, fibroblast growth factor receptor, hepatocyte growth factor receptor, and epidermal growth factor receptor, serve as receptors [83,86-94]. The structures of several of the ligands bound to their capsids have been determined. Presently, the number of published capsid-receptor complex structures at atomic resolution is low (Table 3), but due the recent advancement of cryo-EM this number will increase. In capsid-glycan complex structures, the receptors are bound at or around the 3-fold protrusion (AAV2:heparin, AAV-DJ:heparin) [95-97], at the center of the 3-fold symmetry axis (AAV3:sucrose octasulfate, AAV5:SIA) [98,99], at the base of the 3-fold protrusion (AAV1:SIA) [100], and in a pocket near the 2-fold symmetry axis (MVM:SIA) [101]. The MVM-SIA structure was the first to be determined for a receptor complex. Similar to glycans, cellular protein receptors can bind symmetrical to the capsid, as has been shown recently for the PKD2 domain of AAVR 
to the capsid of AAV2 that interacts with the 3-fold protrusion and the 2-/5-fold wall [102]. However, larger protein receptors might bind with lower copy number to the capsid surface as observed for the transferrin receptor to CPV capsids [83]. The CPV-transferrin complex was the first structure determined for a protein receptor on a parvovirus capsid. The transferrin footprint is located on the 2-/5-fold wall and includes residues 93, 299, and 301 [83,85].

Table 3. Summary of published Parvovirinae capsid-receptor complex structures.

\begin{tabular}{|c|c|c|c|c|c|}
\hline Virus & Receptor & $\begin{array}{c}\text { Structure } \\
\text { Determination } \\
\text { Method }\end{array}$ & Year & Resolution in $\AA$ & Reference \\
\hline AAV2 & AAVR & Cryo-EM & 2019 & 2.8 & Zhang et al. [102] \\
\hline AAV-DJ & $\begin{array}{c}\text { heparinoid } \\
\text { pentasaccharide }\end{array}$ & Cryo-EM & 2017 & 2.8 & Xie et al. [97] \\
\hline AAV1 & SIA & $\begin{array}{c}\text { X-Ray } \\
\text { Crystallography }\end{array}$ & 2016 & 3.0 & Huang et al. [100] \\
\hline AAV5 & SIA & $\begin{array}{c}\text { X-Ray } \\
\text { Crystallography }\end{array}$ & 2015 & 3.5 & Afione et al. [98] \\
\hline AAV3 & $\begin{array}{l}\text { sucrose } \\
\text { octasulfate }\end{array}$ & $\begin{array}{c}\text { X-Ray } \\
\text { Crystallography }\end{array}$ & 2012 & 6.5 & Lerch et al. [99] \\
\hline AAV2 & heparin & Cryo-EM & 2009 & 8.3 & O'Donnell et al. [95] \\
\hline AAV2 & heparin & Cryo-EM & 2009 & 18.0 & Levy et al. [96] \\
\hline $\mathrm{CPV}$ & $\begin{array}{l}\text { transferrin } \\
\text { receptor }\end{array}$ & Cryo-EM & 2007 & 25.0 & Hafenstein et al. [83] \\
\hline MVMp & SIA & $\begin{array}{c}\text { X-Ray } \\
\text { Crystallography }\end{array}$ & 2006 & 3.5 & López-Bueno et al. [101] \\
\hline
\end{tabular}

\subsection{Capsid-Antibody Complex Structures}

The infection by members of the Parvovirinae elicits the host immune response, resulting in both neutralizing and non-neutralizing antibodies raised against their capsids. In the human population, the seroprevalence against different members of the Parvovirinae can be high. For example, while the seroprevalence varies in different regions of the world, up to $80 \%$ of adults have antibodies against B19 [103]. Similar percentages of positivity exist against capsids of different AAV serotypes [104], up to $70 \%$ against the human bocaviruses [105], up to $85 \%$ against the different $\mathrm{BuVs}$ [106], and up to $40 \%$ against human parvovirus 4 [107]. In order to understand the antigenicity of these viruses, the structures of capsid antibodies (whole IgG or FAb) have been determined using cryo-EM (Table 4, Figure 9). The resolutions of these structures range from 23 to $3.1 \AA$ (Table 4). The lower resolution structures are sufficient for the identification of epitopes on the capsid surface to confirm by mutagenesis. The higher resolution structures, e.g., AAV5-HL2476 and B19-human antibody complex, enables analysis of the capsid-antibody interaction for direct identification of contact residues on both sides, namely the capsid surface and residues in the CDRs of the antibody if the antibody sequence is available [108]. The complex structures have shown that almost the entire surface of these capsids can be bound by antibodies, with epitopes across the 2 -fold, the 2-/5-fold wall, 3-fold protrusions, and around the 5 -fold channel (Table 4, Figure 9). This information can inform the engineering of the capsids variants (Section 2.7), the development of vaccines against pathogenic members of the Parvovirinae, and for a better understanding of the viral life cycles, as some antibodies do not neutralize infection or can even further enhance their infection, as reported for B19 and for Aleutian mink disease parvovirus [109,110]. 
Table 4. Summary of published Parvovirinae capsid-antibody structures.

\begin{tabular}{|c|c|c|c|c|c|c|}
\hline Virus & Antibody Name & Year & Binding Region & $\begin{array}{l}\text { Neutralizing for } \\
\text { Infection }\end{array}$ & Resolution in $\AA$ & Reference \\
\hline \multicolumn{7}{|c|}{ Protoparvovirus } \\
\hline $\mathrm{CPV}$ & Fab-E & 2012 & $\begin{array}{l}\text { side of 3-fold } \\
\text { protrusions across } \\
\text { 2-fold axis }\end{array}$ & Yes & 4.1 & Organtini et al. [111] \\
\hline $\mathrm{CPV}$ & Fab-14 & 2009 & 3-fold protrusions & Yes & 12.4 & Hafenstein et al. [84] \\
\hline FPV & Fab-6 & 2009 & 3-fold protrusions & Yes & 18.0 & Hafenstein et al. [84] \\
\hline FPV & Fab-8 & 2009 & 2/5-fold wall & Yes & 8.5 & Hafenstein et al. [84] \\
\hline FPV & Fab-15 & 2009 & 2/5-fold wall & Yes & 10.5 & Hafenstein et al. [84] \\
\hline FPV & Fab-16 & 2009 & 2/5-fold wall & Yes & 13.0 & Hafenstein et al. [84] \\
\hline FPV & Fab-B & 2009 & $\begin{array}{l}\text { 3-fold protrusions } \\
\text { side of 3-fold }\end{array}$ & Yes & 14.0 & Hafenstein et al. [84] \\
\hline FPV & Fab-E & 2009 & $\begin{array}{l}\text { protrusions across } \\
\text { 2-fold axis } \\
\text { side of } 3 \text {-fold }\end{array}$ & Yes & 12.0 & Hafenstein et al. [84] \\
\hline FPV & Fab-F & 2009 & $\begin{array}{l}\text { protrusions across } \\
\text { 2-fold axis }\end{array}$ & Yes & 14.0 & Hafenstein et al. [84] \\
\hline MVMi & B7 & 2007 & $\begin{array}{l}\text { center of 3-fold } \\
\text { symmetry axis }\end{array}$ & Yes & 7.0 & Kaufmann et al. [112] \\
\hline \multicolumn{7}{|c|}{ Bocaparvovirus } \\
\hline HBoV1 & $4 \mathrm{C} 2$ & 2016 & 3-fold protrusions & unknown & 16.0 & Kailasan et al. [113] \\
\hline HBoV1 & 9G12 & 2016 & 3-fold protrusions & unknown & 8.5 & Kailasan et al. [113] \\
\hline HBoV1 & $12 \mathrm{C} 1$ & 2016 & 3-fold protrusions & unknown & 11.9 & Kailasan et al. [113] \\
\hline HBoV1 & $15 \mathrm{C} 6$ & 2016 & $\begin{array}{l}\text { around 5-fold } \\
\text { symmetry axis }\end{array}$ & unknown & 18.6 & Kailasan et al. [113] \\
\hline HBoV2 & $15 \mathrm{C} 6$ & 2016 & $\begin{array}{l}\text { around 5-fold } \\
\text { symmetry axis }\end{array}$ & unknown & 17.8 & Kailasan et al. [113] \\
\hline $\mathrm{HBoV} 4$ & $15 \mathrm{C} 6$ & 2016 & $\begin{array}{l}\text { around 5-fold } \\
\text { symmetry axis }\end{array}$ & unknown & 9.5 & Kailasan et al. [113] \\
\hline
\end{tabular}


Table 4. Cont.

\begin{tabular}{|c|c|c|c|c|c|c|}
\hline Virus & Antibody Name & Year & Binding Region & $\begin{array}{l}\text { Neutralizing for } \\
\text { Infection }\end{array}$ & Resolution in $\AA$ & Reference \\
\hline \multicolumn{7}{|c|}{ Dependoparvovirus } \\
\hline AAV1 & ADK1a & 2015 & 3-fold protrusions & Yes & 11.0 & Tseng et al. [114] \\
\hline AAV1 & $4 \mathrm{E} 4$ & 2013 & $\begin{array}{l}\text { protrusions across } \\
\text { 2-fold axis }\end{array}$ & Yes & 12.0 & Gurda et al. [115] \\
\hline AAV1 & $5 \mathrm{H} 7$ & 2013 & $\begin{array}{l}\text { center of 3-fold } \\
\text { symmetry axis }\end{array}$ & Yes & 23.0 & Gurda et al. [115] \\
\hline AAV2 & C37-B & 2013 & 3-fold protrusions & Yes & 11.0 & Gurda et al. [115] \\
\hline AAV2 & A20 & 2012 & $2 / 5$-fold wall & Yes & 8.5 & McCraw et al. [116] \\
\hline AAV5 & ADK5a & 2015 & 2/5-fold wall & Yes & 11.0 & Tseng et al. [114] \\
\hline AAV5 & $\mathrm{ADK} 5 \mathrm{~b}$ & 2015 & \multirow{4}{*}{$\begin{array}{l}\text { 2/5-fold wall to 5-fold } \\
\text { symmetry axis } \\
\text { 3-fold protrusions } \\
\text { 2/5-fold wall in a } \\
\text { tangential orientation } \\
\text { center of 3-fold } \\
\text { symmetry axis }\end{array}$} & Yes & 12.0 & Tseng et al. [114] \\
\hline AAV5 & HL2476 & 2018 & & Yes & 3.1 & Jose et al. [108] \\
\hline AAV5 & $3 \mathrm{C} 5$ & 2013 & & No & 16.0 & Gurda et al. [115] \\
\hline AAV6 & $5 \mathrm{H} 7$ & 2013 & & unknown & 15.0 & Gurda et al. [115] \\
\hline AAV8 & ADK8 & 2011 & \multirow{2}{*}{$\begin{array}{l}\text { 3-fold protrusions } \\
\text { center of 3-fold } \\
\text { symmetry axis }\end{array}$} & Yes & 18.7 & Gurda et al. [118] \\
\hline AAV9 & PAV9.1 & 2018 & & Yes & 4.2 & Giles et al. [119] \\
\hline \multicolumn{7}{|c|}{ Erythroparvovirus } \\
\hline B19 & human Fab & 2018 & $\begin{array}{l}\text { around 5-fold } \\
\text { symmetry axis }\end{array}$ & Yes & 3.2 & Sun et al. [120] \\
\hline
\end{tabular}




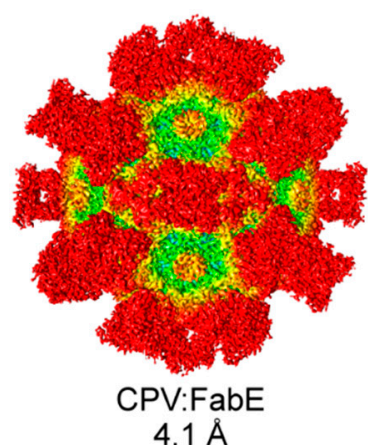

$4.1 \AA$

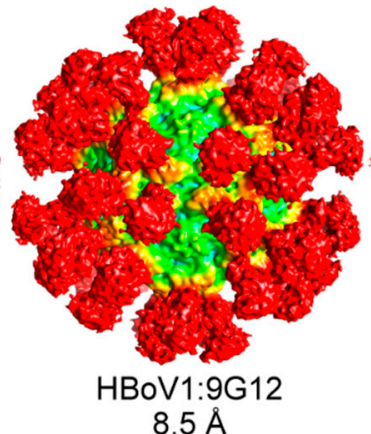

$8.5 \AA$

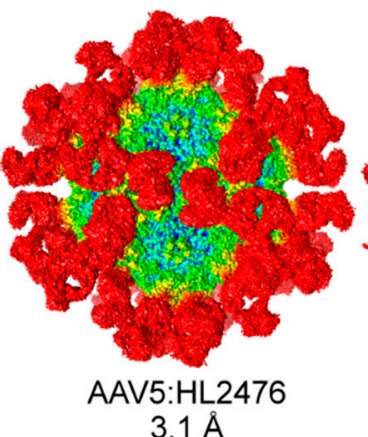

$3.1 \AA$

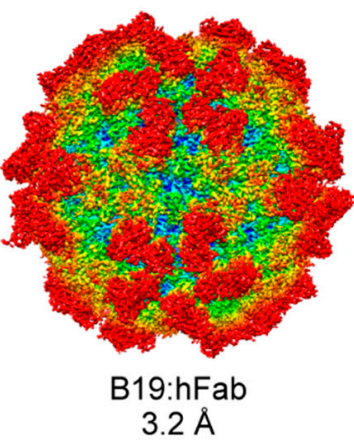

$3.2 \AA$

Figure 9. Parvovirinae-antibody complex structures. The highest resolution complex structures available for Protoparvovirus, Bocaparvovirus, Dependoparvovirus, and Erythroparvovirus are shown. The cryo-EM density maps are viewed down the icosahedral 2-fold axis and are colored according to radial distance from the particle center (blue to red), as indicated by the scale bar. The FAbs decorating the capsid surface are in red. The FAbs bind across the icosahedral 2-fold (e.g., CPV:FAbE), the 2-/5-fold wall (HBoV1:9G12), the 3-fold (AAV5:HL2476), and 5-fold depression (B19:hFab). The images were generated using Chimera [78]. (CPV: EMD-6629, B19: EMD-9110).

\subsection{Engineering of Parvovirus Capsids to Create Biologics}

The development of Parvovirinae members as biologics is primarily focused on the engineering of capsids of members that can be used as viral vectors in gene delivery applications, such as the AAVs [121], or more recently also bocaviral vectors [122]. For such vectors, a transgene expression cassette is packaged into the capsids instead of the wt viral genome [123]. These vectors are used to infect a desired target tissue to achieve long-term expression of the transgene to correct monogenetic diseases.

Following the discovery that AAV capsids become phosphorylated at tyrosine residues after cell entry subsequently leading to their degradation following lysine ubiquitination, reducing the transgene expression [124,125], the structural information of the AAV capsids was used to identify surface exposed tyrosines for modification [126]. Mutational analysis of these tyrosine residues to phenylalanine led to the development of engineered capsids that showed improved transduction efficiencies compared to vectors packaged into wt capsids [126]. Subsequent mutation of capsid surface serine, threonine, and lysines further improved transduction efficiency [127,128]. Another application of structure information for vector engineering is the modification of AAV capsids to escape pre-existing neutralizing antibodies utilizing the footprints mapped by cryo-EM. As mentioned above, a large percentage of the human population possesses anti-capsid antibodies against one or more AAV serotype due to natural exposures. These pre-existing antibodies bind to the capsids of administered AAV vectors and disrupt multiple steps required for successful transgene delivery, including receptor attachment, post-entry trafficking, and capsid uncoating events [129]. To circumvent these inhibitory events, different strategies have been developed, including the utilization of immunosuppressants [130-133], the utilization of alternative natural AAV capsids that are not detected by the pre-existing human antibodies [68], the use of empty capsids as decoys [134], and the structure-guided modification of the antigenic sites on the surface of the capsids [135]. For the latter strategy, the antigenic sites are identified using monoclonal antibodies, as mentioned in Section 2.6. By rational design or directed evolution, these sites can be changed to obtain new variants with escape phenotypes while maintaining infectivity $[108,135,136]$. While the majority of capsid engineering has been with AAVs, because of their high seroprevalence, vectors based on bocaviruses will face similar obstacles and require solutions to escape pre-existing immunity in the human population.

Another purpose for capsid engineering is the retargeting of vectors to specific receptors or tissues to restrict the broad tissue tropism of some AAV serotypes $[137,138]$. This can be achieved by insertion of specific targeting peptides into capsid surface loops, especially in the apexes of VR-IV and VR-VIII (Figure 7), e.g., for AAV2 variants 7m8 or r1c3 [138-140], directed evolution for a specific cell type [141], or structure guided approaches [142]. For some of these engineered AAVs, the structures of 
the modified capsids have been determined, e.g., AAV2.5, the first structure-guided in silico designed $\mathrm{AAV}$ gene delivery vector [58], AAV-DJ, a chimera created through random homologous recombination followed by directed evolution [67], and AAV9-L001, an AAV9 variant with a peptide lock to prevent off-target delivery [66].

\section{Densovirinae}

The Densovirinae encompasses members infecting exclusively invertebrates [143]. Currently, the subfamily consists of five genera, clustering into two separate lineages; Ambi- and Iteradensovirus infecting arthropods and echinoderms in the first, and Brevi-, Hepan-, and Penstyldensovirus infecting various arthropods, e.g., decapod crustaceans and insects in the second lineage (Figure 1) [1]. However, as the number of invertebrate-infecting parvoviruses from diverse host species has increased, the heterogeneity of the subfamily has become apparent, questioning the monophyly of prior genera, such as Ambidensovirus [1,13] (Figure 1). The second lineage includes additional, yet unclassified virus species. These viruses comprise the recently discovered starfish densoviruses of the species Aster rubens and a vertebrate-infecting parvovirus clade named Chapparvovirus after the Chiroptera-Aves-Porcine acronym based on the host species where these viruses were first discovered (Figure 1) [144]. Densoviral genomes vary in organization, unlike the subfamily Parvovirinae, and have a wider size range at between 3.9 and $6.3 \mathrm{~kb}$. They also have either ambisense or monosense transcription. The left-hand side ORF contains the $n s$ gene and expresses up to five proteins [145]. The right-hand side ORF is cap and encodes up to four VPs (Figure 3). All densoviruses discovered to date are capable of autonomous replication and pathogenic [1].

\subsection{The Densovirinae Utilize Diverse Strategies for VP Expression}

Densoviruses, like their vertebrate counterparts, have evolved diverse expression strategies to overcome the limitation of the coding capacity imposed by their small genome size (Figure 3) [146]. The transcription strategy has been determined for four of the five densovirus genera, and has not been experimentally derived for the Hepandensovirus or the new starfish densoviruses (GenBank accession numbers: MF190038 and MF190039). Overall, densoviral transcription relies more on leaky scanning than the alternative splicing utilized by the Parvovirinae (compare Figure 2 to Figure 3) [143]. This difference is an adaption to the host because invertebrates possess a lower percentage of alternatively spliced genes compared to vertebrates [147]. Consistently, the chapparvoviruses mentioned above (Figures 1 and 3) utilize alternative splicing as the major strategy to express their VPs [148]. As for the Parvovirinae, the smallest VP is the one with the largest incorporation into the capsid for densoviruses.

The Ambidensovirus display the most variable VP expression strategies, likely because the genus currently also contains the most members. Because of their unique ambisense genome organization, the cap gene is located on the opposite strand relative to the $n s$ gene, both driven by the furthest upstream promoter embedded in the partially double-stranded region of the ITRs (Figure 3). There are three different VP expression strategies established for this genus [1]. Members of the first group, e.g., Galleria mellonella densovirus (GmDV), express a minor capsid VP1 from an unspliced transcript of the p93 promoter. Three additional VPs, VP2, VP3, and VP4 (major capsid VP), are expressed by leaky scanning $[7,149]$. These are reported to be incorporated into the capsid at a 1:9:9:41 ratio [7]. The second group, including Periplaneta fulliginosa densovirus (PfDV) and Acheta domestica densovirus (AdDV), has a split cap ORF for the minor capsid VPs joined by splicing of transcripts, with VP2, VP3, and VP4 expressed from leaky scanning of the unspliced transcript in case of AdDV. This results in both VP1 and VP2 having unique N-terminal regions. These VPs are reportedly incorporated into the AdDV capsid at a 1:11:18:30 ratio. In comparison, both VP1 and VP2 are translated from spliced transcripts in PfDV (Figure 3) $[8,150,151]$. The third group, represented by Culex pipiens densovirus of Dipteran ambidensovirus 1, has four VPs expressed from one unspliced transcript by leaky scanning, giving rise to a VP1, VP2, VP3, and a small $12 \mathrm{kDa}$ VP4, which is a minor capsid protein with approximately the same incorporation as VP1. VP2 and VP3 are reportedly equally abundant in the capsid [145]. 
The Iteradensoviruses are related to the ambidensoviruses and have a similar VP expression strategy despite packaging monosense genomes. Although the exact number of VPs expressed is unknown, they use leaky scanning from the same unspliced transcript (Figure 3) [152]. SDS-PAGE analysis of Bombyx mori densovirus 1 (BmDV1) show three VPs, VP1, VP2, and VP3 [153]. Penstyl- and Brevidensovirus transcribe only a single unspliced VP transcript resulting in a single VP that is among the smallest in the Parvoviridae at 329 aa and 358 aa, respectively $[154,155]$. In contrast, the Hepandensovirus cap ORF encodes a large VP1, e.g., with hepatopancreatic necrosis virus having a VP1 of 830 aa from the largest Parvoviridae genome of $6.3 \mathrm{~kb}[146,156]$. The two recently discovered densoviruses from the starfish species Aster rubens, closely related to the Hepandensovirus (Figure 3), both encode the largest VPs of the family, with 983 and 988 aa (GenBank accession numbers: MF190038 and MF190039).

\subsection{Densovirinae Capsid Structures Display Distinct Surface Morphology}

In contrast to the Parvovirinae, for which numerous capsid structures have been determined (Table 1), only four crystal structures are available for Densovirinae (Table 5). In addition, two low resolution structures have been determined using cryo-EM (Table 5). The high-resolution structures are for Ambidensovirus members GmDV at $3.7 \AA$ [7] and AdDV $3.5 \AA$ A resolution [8]; Iteradensovirus member BmDV1 at $3.1 \AA$ A resolution [9]; and Penstyldensovirus member Penaeus stylirostris densovirus (PstDV) at $2.5 \AA$ [157]. Two of these structures, GmDV and AdDV, were determined for DNA packaged (full) infectious virions. AdDV showed three pyrimindine bases ordered within the luminal surface at the 3-fold symmetry axis [8]. As previously stated, this ordering is unexpected given the lack of icosahedral symmetry for the single copy of the packaged genome. The cryo-EM structures are for Ambidensovirus member Junonia coenia densovirus (JcDV) at $8.7 \AA$ A resolution [158] and Brevidensovirus member Aedes albopictus densovirus (AalDV2) at $15.6 \AA$ resolution [159].

Table 5. Capsid structures of Densovirinae determined to date.

\begin{tabular}{|c|c|c|c|c|c|c|}
\hline Virus & Empty / Full & $\begin{array}{l}\text { Structure } \\
\text { Determination } \\
\text { Method }\end{array}$ & Year & $\begin{array}{c}\text { Resolution } \\
\text { in } \AA\end{array}$ & PDB-ID & Reference \\
\hline \multicolumn{7}{|c|}{ Ambidensovirus } \\
\hline AdDV & Full & $\begin{array}{c}\text { X-Ray } \\
\text { Crystallography }\end{array}$ & 2013 & 3.5 & 4MGU & Meng et al. [8] \\
\hline GmDV & Full & $\begin{array}{c}\text { X-Ray } \\
\text { Crystallography }\end{array}$ & 1998 & 3.6 & 1DNV & Simpson et al. [7] \\
\hline $\mathrm{JcDV}$ & Empty & Cryo-EM & 2005 & 8.7 & N/A & Bruemmer et al. [158] \\
\hline \multicolumn{7}{|c|}{ Brevidensovirus } \\
\hline AalDV2 & Full & Cryo-EM & 2004 & 15.6 & N/A & Chen et al. [159] \\
\hline \multicolumn{7}{|c|}{ Iteradensovirus } \\
\hline BmDV1 & Empty & $\begin{array}{c}\text { X-Ray } \\
\text { Crystallography }\end{array}$ & 2011 & 3.1 & 3P0S & Kaufmann et al. [9] \\
\hline \multicolumn{7}{|c|}{ Penstyldensovirus } \\
\hline PstDV & Empty & $\begin{array}{c}\text { X-Ray } \\
\text { Crystallography }\end{array}$ & 2010 & 2.5 & $3 N 7 X$ & Kaufmann et al. [157] \\
\hline
\end{tabular}

Similarly to the Parvovirinae VP structures, a significant portion of the N-terminal region of the major capsid VP is also disordered in the densoviruses, e.g., 23 aa in GmDV and AdDV, 1031 aa in PstDV, and 42 in BmDV1 [7-9,157]. Again, as for the Parvovirinae, disorder predictions for these viruses show disorder between the $\mathrm{N}$ and C-terminus at the glycine-rich region (Figures 10 and 11). The glycine-rich region is significantly shorter in the densoviruses, e.g., 6 aa in GmDV and 7 aa in AdDV compared to 12 aa in CPV, but still results in a lack of structure order (Figures 10 and 11). Interestingly, the BmDV1 structure currently represents the only parvoviral VP structure, where the last 
40 C-terminal residues are also disordered. The C-terminal residue of densoviral VP structures, with the exception of BmDV1, are positioned near the 2-fold symmetry axis, similarly to the VP structures of the Parvovirinae, and exposed on the capsid surface [7-9,157].
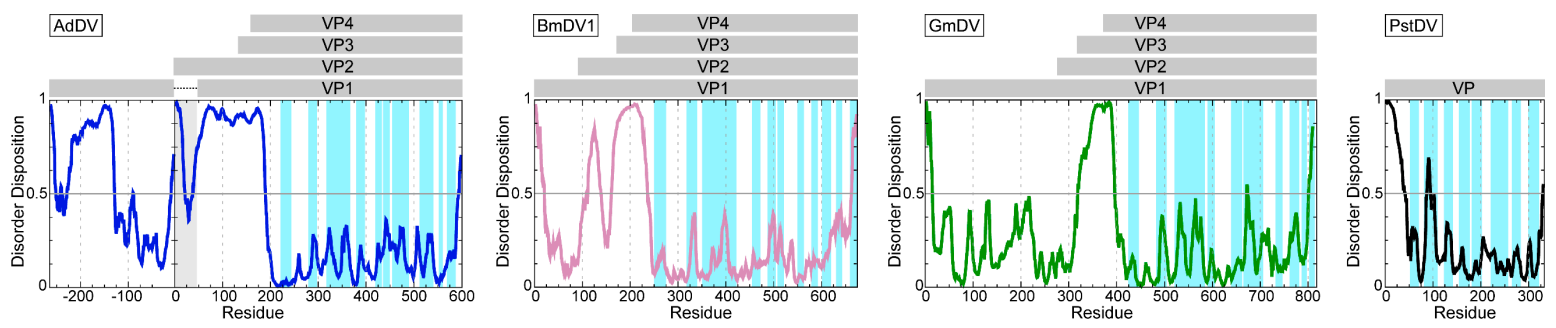

Figure 10. Disorder prediction for densoviruses. AdDV (blue), BmDV1 (pink), GmDV (green), and PstDV (black) VP1. The PONDR_fit application was utilized [72]. Regions above 0.5 on the Y-axis are predicted to be disordered. The approximate locations of the VPs are indicated in the grey bars above. In case of AdDV, both VP1 and VP2 have unique N-terminal regions. The regions highlighted in light blue in the disorder plot indicate the locations of the surface exposed loops, their apexes are VRs.

BgDV
DpDV
SiDV
PiDV
MIDV
GmDV
AdDV
BmDV5
BmDV1
SfDV
DpDV
HaDV
AaeDV
PstDV
HPV
CsPVLV
MsPVLV

MSAPEAIVTGKRGAEEPDSASTPTKKNKPSEHSGSALPGTSGNTDGSMGSS MSH - RYOGPPPPORPNWSKLNSSORAYAIROYNIGRTRRNLPIFVLGGGGDRIDSSASEOSSEHSSG MAPPVSMDKS - . . - . - - TSGAST - . - - SGTSN - . - . - . - - KGGKGIKRQKTSDSGIAEGG




MS - - - LPGT - . - - - GSGTSS - - - -


MSEDIQPMETV - - - -GATDTGGGAQVDPRTGGQAAGGSGGMGAGG - - - - - SANDG MSEDIQPMETV - - - -GATDTGAGAQVDPRTGGQAAGGSGGMGAGG - - - - - SANDG MSDEEVPMDTAAAAAGATDIGGGPOVDPRSGGOAAGG - - -MGAGG - - - - - - AANDG MSQENVPMDTE - - - - GATDVGGGAQVDPRSGGQAAGG - - MGGGG - - - - - AANDG M- - - - - - DMV - - - - - - - - DQPRAGGAPSGG - - SSSGGTGSNMGDVYAG MADSTSMDHDGEQRGTKRKRGAGAGGSGAGIGKGNSNSVKEGYG MCADSTRASPRKRSRRDAHNEDEEHAEGSSG MASAAPTPMETSEPGVTAAPHQKSAAGGGGGGGGSGGETAGYG MVEEEITPVEAEEQGAGRSARDVSGGSGGGGGGGGLG MAEEETITPVDAAQEGQEPMDTNRSRGGGSGGGGGLG

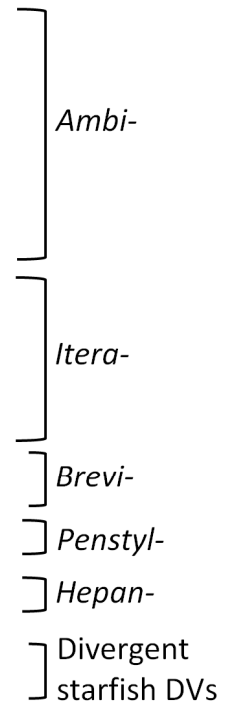

Figure 11. The N-termini of the major VPs of the Densovirinae. For each genus a selection of available VP sequences are shown for the N-terminal 20-50 amino acids. All glycine residues are in red.

The core of the densoviral VP is an eight-stranded jelly roll fold with an additional N-terminal strand, $\beta \mathrm{A}$, and with large loops connecting the strands, as described above for the Parvovirinae (Figure 12). In the GmDV VP structure, considered the Densovirinae prototype, the EF and GH loops are further divided into five and four sub-loops, respectively (Figure 12). While the GH loop is the longest and forms most of the surface features, its length is significantly shorter compared to the corresponding loop in the Parvovirinae at 97 aa compared to 226 aa in CPV. Similar to the Parvovirinae, the GH loop is the most variable among ambidensoviruses, although VRs have not been defined, as has been done for the former viruses [7]. At the 2-fold symmetry axis, similarly to vertebrate parvovirus VPs, the densovirus structures have an alpha helix $(\alpha \mathrm{A})$. As a common feature for these viruses, a second $\alpha$-helix is contained within the EF loop, with PstDV containing a third helix in the CD loop (Figure 12) [7-9,157].

An important and differentiating feature of the densoviral VP is the domain swapping observed at their N-terminus [7-9,157] (Figure 13). The $\beta$ A strand of the swapped domain interacts with the 2 -fold symmetry related VP's $\beta B$ strand rather than the intra VP $\beta A$ and $\beta B$ interaction observed in the Parvovirinae (Figure 13). Thus, the luminal $\beta$ BIDG sheet of the jelly roll core is still extended into 
a $\beta$ ABIDG sheet, as in the Parvovirinae, and the first observed N-terminal residue is also positioned underneath the 5-fold axis, but in this case, under that of the neighboring VP subunit (Figure 13). In the case of the GmDV VPs, the domain swapping is proposed to create additional hydrogen bonds with the 2-fold related VP's $\beta \mathrm{B}$ imparting increased stability [7]. A re-arrangement into an unswapped conformation is proposed to be required for VP1u externalization, although there is no experimental proof that this occurs [7]. In contrast to GmDV, in PstDV the distance between the swapped N-terminus and the $\beta \mathrm{B}$ of the neighboring VP is too large to form hydrogen bonds [157], while in AdDV, the $\beta$ A contains three proline substitutions compared to GmDV, P24, P26, and P28, which makes such interactions impossible. In these two viruses, divalent cations observed at the N-terminus are hypothesized to confer stability [7,157].

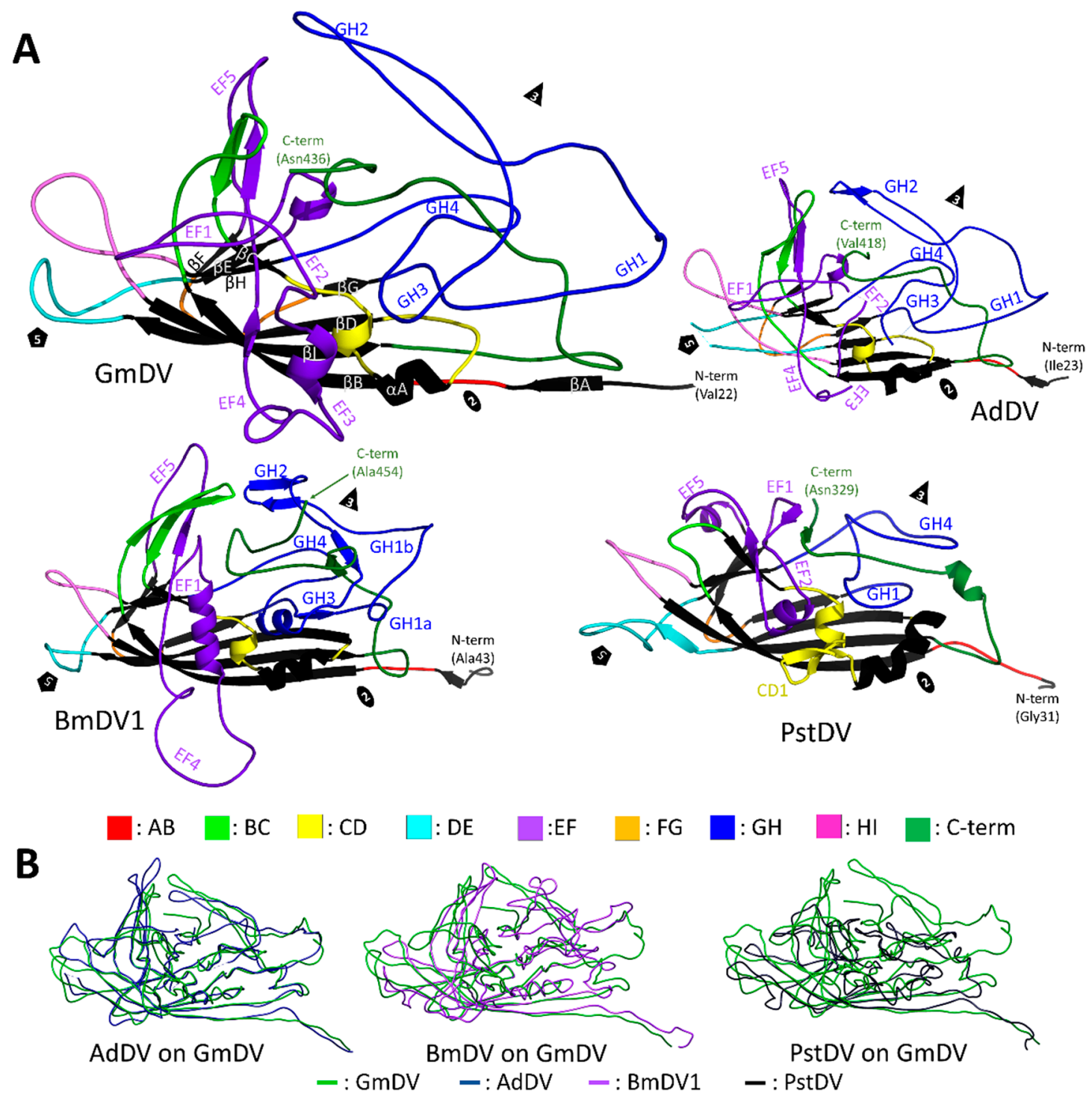

Figure 12. The densovirus VP structure. (A) Cartoon ribbon diagrams of the ordered common VP structures of GmDV and AdDV (top), BmDV1 and PstDV (bottom). The first ordered N-terminal residue and $\mathrm{C}$-terminal residue are labeled. The conserved $\beta$-core and $\alpha \mathrm{A}$ helix are colored in black and labeled in GmDV. Loops and subloops within the large loops are as colored in the key at the bottom and EF and GH sub-loops are labeled. The approximate 5-fold symmetry axis is marked by a pentagon, the 3-fold by a triangle, and the 2-fold by an ellipsoid. (B) A GmDV VP structure (Ambidensovirus) superimposed on the VPs of AdDV (left), BmDV1 (middle), and PstDV (right). Conformational diversity on the surface loops is evident, especially between GmDV and BmDV, and GmDV and PstDV. 


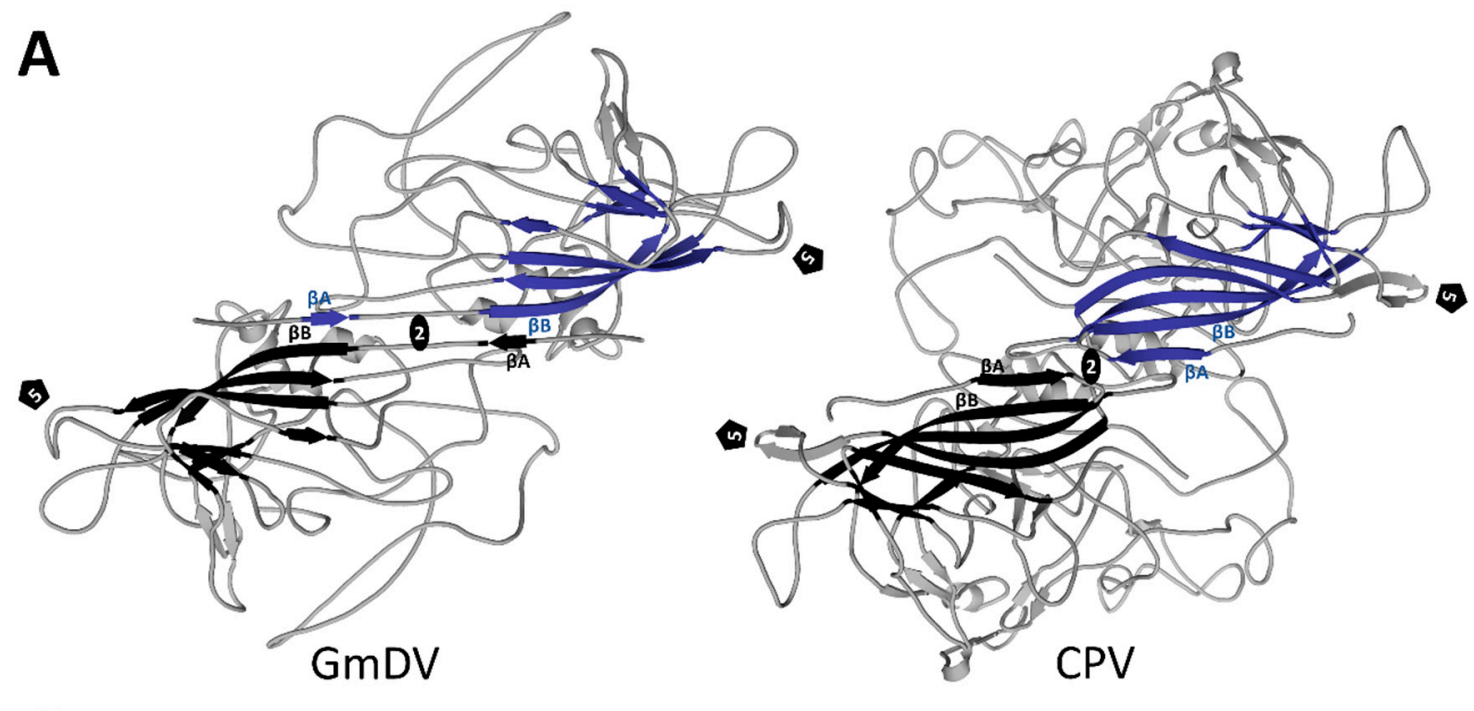



GmDV



CPV

Figure 13. Multimeric interactions of densoviral and parvoviral VPs. (A) Ribbon cartoon diagrams of the interactions between $\beta \mathrm{A}$ and $\beta \mathrm{B}$ at the 2-fold symmetry axis of GmDV and CPV. The eight-stranded core, with the additional $\beta \mathrm{A}$, which performs the domain swapping, are colored blue and black. (B) Interaction of three 3-fold symmetry related VPs for GmDV and CPV. The open annulus-like structure at the 3-fold axis of the densovirus trimer compared to the more closed arrangement in the vertebrate parvoviruses is evident. The triangle indicates the 3 -fold axis and the pentagon the 5-fold axis.

The sequence identity among the VP monomers of the Densovirinae ranges from $\sim 7 \%$ to $20 \%$ (Table 6). The structural similarity is higher and ranges from the value anticipated from the eight-stranded $\beta$-barrel core and $\alpha$ A helix at $20 \%$ to $~ 70 \%$ (calculated by DALI pairwise alignments [160]) between the PstDV and GmDV from different genera, and GmDV and AdDV from the same genus, respectively (Table 6). The structural diversity of densoviruses is mostly attributable to the $\mathrm{CD}, \mathrm{EF}$, and GH loops (Figure 12). In the PstDV VP structure, all loops are shorter than in the other three high-resolution structures due to the smaller size of the VP (Figures 3 and 12). When the GmDV VP structure is superimposed to that of $\mathrm{CPV}$, up to $148 \mathrm{C} \alpha$ atoms (36\%) are similarly positioned (not shown). This is remarkable given the lower structure similarities between members of the subfamily (Table 6). The majority of the residues are located in the core [7]. 
Table 6. Sequence identity and structural similarity for densoviruses.

\begin{tabular}{ccccc}
\hline \multicolumn{5}{c}{ Structural Similarity [\%] Derived from DALI Z-Scores } \\
\hline GmDV & GmDV & AdDV & BmDV1 & PstDV \\
AdDV & 20 & 68.2 & 45.6 & 44.2 \\
BmDV1 & 11 & 10 & 7 & 20.4 \\
PstDV & 9.2 & 9 & 24.4 \\
\hline \multicolumn{5}{c}{ Sequence identity on superposed C-alphas atoms [\%] } \\
\hline
\end{tabular}

The overall capsid morphology of densoviruses can be divided into two types: One is a large, with diameter of $\sim 235$ to $\sim 260 \AA$ in the depressions and protrusions, respectively, while the other one is 215 to $250 \AA$, being the smallest capsids so far described for the Parvoviridae (Figure 14). For the larger capsids, including GmDV, AdDV, and BmDV1, the capsid surface is smooth with small spike-like protrusions surrounding the 5-fold axes. In GmDV the spikes, formed by the EF4 sub-loop, appear to be smaller compared to BmDV1 and AdDV, due to the protruding GH2 sub-loop filling up the depression surrounding them. In GmDV, a smaller second protrusion is formed by the $\mathrm{BC}$ loop. There is a depression at the 2-fold axes (Figure 14). In the second group, containing PstDV and AalDV2 (not shown), there are prominent protrusions surrounding the 5-fold axis, forming two rim-like concentric circles. The 2- and 3-fold symmetry axes have depressions (Figure 14). Approximating with capsid size, there is a variance among luminal volume and surface area of densovirus particles consistent with the range of packaged genome (Table 7).

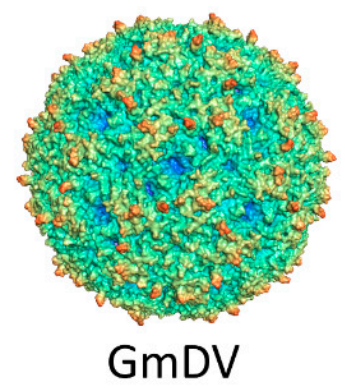

(3.6 A)

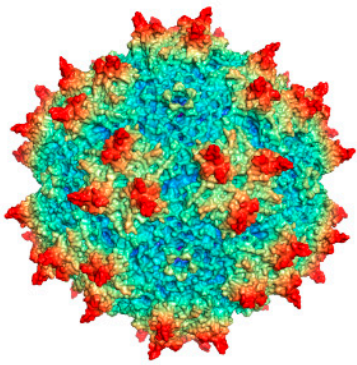

AAV2

(3 ̊̊)

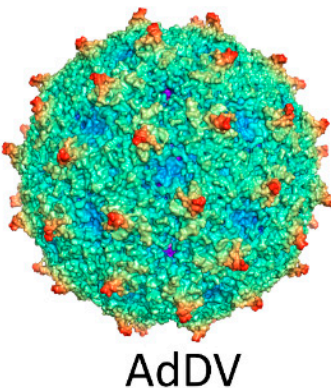

$(3.5 \AA)$

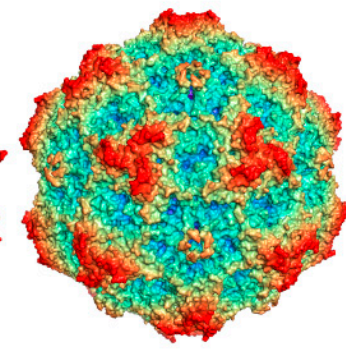

CPV

(3 Å)
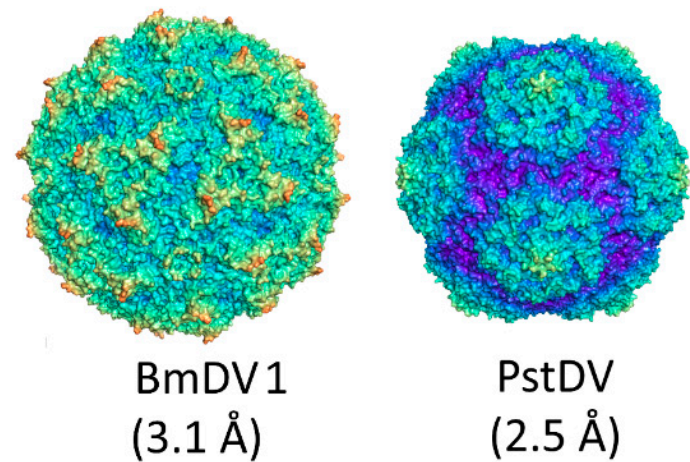

PstDV
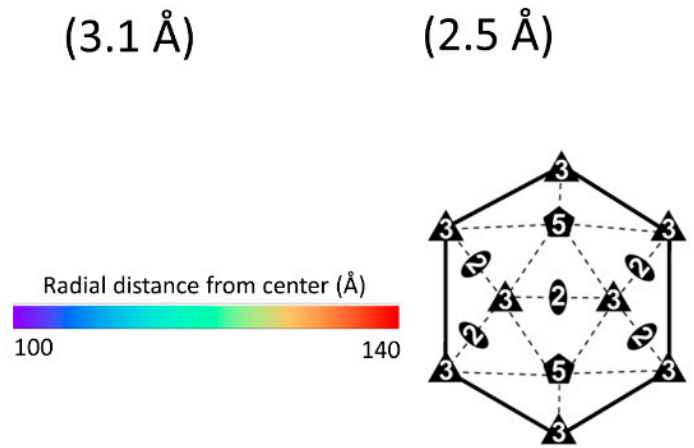

Figure 14. Densoviral capsid structures. The capsid surface images of GmDV, AdDV, BmDV1, and PstDV. The resolution of each structure is in parenthesis. The AAV2 and CPV capsid images are shown for comparison. The scale bar shows the radial distance (from the capsid center) used for the images. An icosahedral symmetry diagram indicating the positions of the visible symmetry axes on the capsid images are shown at the bottom right hand side. 
Table 7. Dimensions, DNA content, and taxonomy of densovirus capsid structures.

\begin{tabular}{|c|c|c|c|c|c|}
\hline & $\begin{array}{c}\text { Inner Radius } \\
\text { (§) }\end{array}$ & $\begin{array}{c}\text { Inner Surface } \\
\text { Area }\left(\mathrm{nm}^{2}\right)\end{array}$ & $\begin{array}{l}\text { Inner Volume } \\
\left(\mathrm{nm}^{3}\right)\end{array}$ & $\begin{array}{c}\text { Genome Size } \\
\text { (nt) }\end{array}$ & Genus \\
\hline GmDV & 98.7 & 1223.2 & 4022.6 & 6039 & Ambidensovirus \\
\hline AdDV & 91.7 & 1056.2 & 3227.8 & 5425 & Ambidensovirus \\
\hline BmDV1 & 98.7 & 1224 & 4027.5 & 5076 & Iteradensovirus \\
\hline PstDV & 87.6 & 963.3 & 2811.5 & 3914 & Penstyldensovirus \\
\hline $\mathrm{CPV}$ & 92.9 & 1084.8 & 3359.5 & 5323 & Protoparvovirus \\
\hline AAV2 & 89.9 & 1014.9 & 3040.4 & 4679 & Dependoparvovirus \\
\hline
\end{tabular}

The 5-fold symmetry axis of the Densovirinae, similar to the Parvovirinae, contains a channel with a direct opening to the surface [7-9,157]. Its size is also similar, at $9 \AA$ in diameter in GmDV, which is the same as for CPV. The inner wall of the channel is lined by large hydrophobic residues in all four structures, proposed to provide an interacting surface to the glycine-rich stretch of residues when the N-terminus is externalized. So far, the only densovirus for which PLA2 externalization has been investigated is AdDV. Meng et al. [8] found that heating of infectious AdDV particles to $70{ }^{\circ} \mathrm{C}$ resulted in increased PLA2 activity accompanied by genome ejection, while capsids remained intact. Both Simpson et al. and Meng et al. [7,8] speculated that the channel might also become occupied by stretches of VP2 and VP3 amino acids, although the role of these is currently unknown.

At the 3-fold symmetry axes, a $\beta$-annulus-like structure is present in densoviruses instead of the protrusions at or surrounding this region observed in the Parvovirinae (Figures 13 and 14). This is similar to the 3-fold region of (+)ssRNA viruses, such as Tomato Stunt Mosaic Virus of Tomubusviridae [161] and Southern Bean Mosaic Virus of Solemoviridae [162]. The annulus is formed by charged and flexible residues, with an $\sim 10-\AA$ wide opening in GmDV. This opening is less pronounced in BmDV1 and shows even less annulus-like appearance in the case of PstDV, where the shorter GH loops do not interdigitate between neighboring monomers [157].

\subsection{Functions Associated with Densoviral Capsid Proteins}

Compared to members of the Parvovirinae, little is known about the functions of densovirus VPs and the available information is mostly based on studies of members of Ambidensovirus. By comparing the VP4s of two closely related lepidopteran ambidensoviruses, GmDV and JcDV, eight variable, exposed regions were identified [158]. One of these was located at the 5-fold symmetry axis, in the DE loop, five in vicinity of the protrusions surrounding it, i.e., the EF1, EF2, and the GH1 sub-loops, one at the 3-fold axis, and one in the depression at the 2-fold axis. Attempts to mutate residues in JcDV to their counterpart in GmDV showed that mutated residues in the GH loop resulted in a decrease of the ability to cross the host midgut epithelium and a reduction of JcDV virulence if introduced through the natural, gastro-intestinal pathway [163]. When ex vivo infecting Spodoptera frugiperda hosts, the mutated virus became mis-targeted and accumulated in subcellular compartments of midgut epithelial cells instead of reaching their target receptors in the basal tight junctions [164].

Recent experiments on Blattella germanica densovirus 1 (BgDV1) of the genus ambidensovirus have shown that an in silico predicted, bipartite nuclear localization signal (NLS) in the C-terminus of all four VPs has an effect on the import of VP monomers to the assembly site located within the nucleus. In the same viral particles a nuclear export signal (NES) was also identified that is located in the VP2 unique N-terminal region (VP2u) and was proven to function during nuclear egress of assembled BgDV1 particles. These results imply that the ambidensoviral VP2u possesses an important function for intracellular trafficking of assembled progeny virions. For this purpose the VP2u domain likely needs to be externalized, similarly to VP1u [165]. Interestingly, a functional NLS has been described at the N-terminus of hepatopancreatic parvovirus (HPV) [166]. Recently the Helicoverpa armigera densovirus 2 (HaDV2) VPs were shown to enhance the structural promoter activity by 35 -fold 
compared to the activation by NS [167]. A similar role in transcriptional regulation by capsids has been proposed for the AAVs of the Parvovirinae [168].

\section{Summary}

By the end of 2018, more than 100 capsid structures were published for the Parvoviridae (Figure 15). This includes lower resolution cryo-EM capsid structures alone or in complex with receptor or antibody molecules, and near-atomic and atomic resolution cryo-EM and crystal structures (Table 1, Table 3, Table 4, and Table 5). The VP coordinates for the first parvovirus capsid structure, CPV, was determined by X-ray crystallography [38]. In the following two decades, X-ray crystallography remained the method of choice to determine high-resolution capsid structures. The first parvoviral capsid structure determined by cryo-EM was for the Aleutian Mink Disease Virus (ADV) and displayed the general features of the surface of the parvoviral capsid at $22 \AA$ resolution [169]. The first boost in the use of cryo-EM in structural parvovirology occurred after its utility for mapping the epitopes of monoclonal antibodies onto the capsid became evident. A second boost occurred with the development of direct electron detectors and their ability to record movie frames that can subsequently be aligned, which resulted in atomic resolution structures, for example, the structure of the AAV2-L336C variant at $1.86 \AA$ resolution. This structure is currently the highest resolution parvovirus capsid structure, as well as all viruses (Figure 15). The most important aspect of the advances made in structural parvovirology is the ability to use the information obtained to functionally annotate the life cycle of these viruses. This ability provides the tools required to develop biologics in the form of vaccines or inhibitors for pathogenic members, for example, B19 and densoviruses, or gene delivery vehicles with improved efficacy for non-pathogenic members, such as the AAVs.

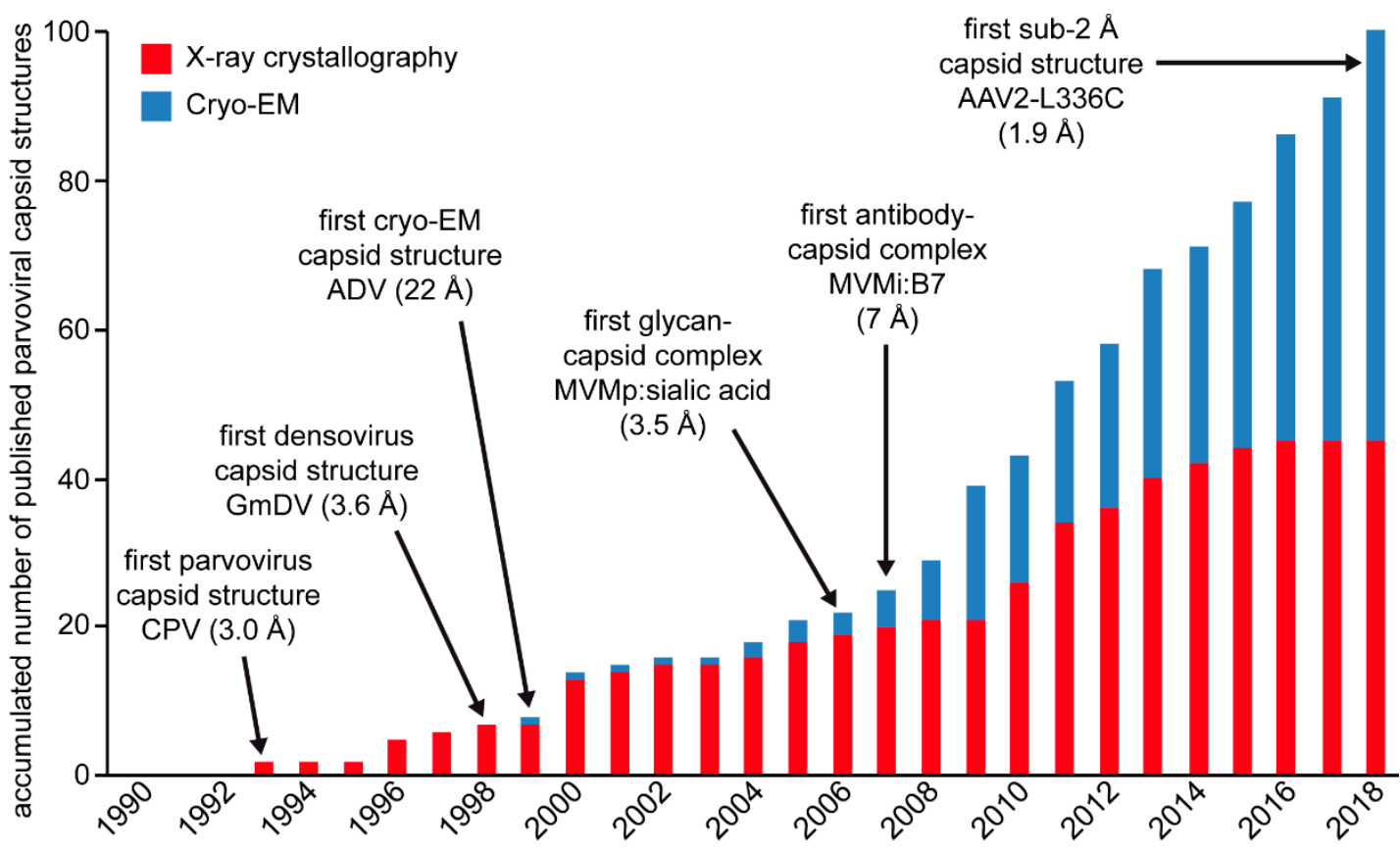

Figure 15. Overview of published parvoviral capsid structures since 1990. Structures determined by $\mathrm{X}$-ray crystallography are shown in red and structures determined by cryo-EM in blue. Important milestones of structural parvovirology are indicated.

Funding: This work was supported by NIH R01 grants GM109524 and GM082946, and the University of Florida College of Medicine.

Conflicts of Interest: MAM is a SAB member for Voyager Therapeutics, Inc., and AGTC, has a sponsored research agreement with AGTC, Voyager Therapeutics, and Intima Biosciences, Inc., and is a consultant for Intima Biosciences, Inc. MAM is a co-founder of StrideBio, Inc. This is a biopharmaceutical company with interest in 
developing AAV vectors for gene delivery application. MAM and MM have IP in AAV technology, some licensed to Biotechnology companies.

\section{References}

1. Cotmore, S.F.; Agbandje-McKenna, M.; Canuti, M.; Chiorini, J.A.; Eis-Hubinger, A.M.; Hughes, J.; Mietzsch, M.; Modha, S.; Ogliastro, M.; Penzes, J.J.; et al. ICTV virus taxonomy profile: Parvoviridae. J. Gen. Virol. 2019, 100, 367-368. [CrossRef] [PubMed]

2. Camacho, C.; Coulouris, G.; Avagyan, V.; Ma, N.; Papadopoulos, J.; Bealer, K.; Madden, T.L. BLAST+: Architecture and applications. BMC Bioinform. 2009, 10, 421. [CrossRef] [PubMed]

3. Xie, Q.; Bu, W.; Bhatia, S.; Hare, J.; Somasundaram, T.; Azzi, A.; Chapman, M.S. The atomic structure of adeno-associated virus (AAV-2), a vector for human gene therapy. Proc. Natl. Acad. Sci. USA 2002, 99, 10405-10410. [CrossRef] [PubMed]

4. Kaufmann, B.; Simpson, A.A.; Rossmann, M.G. The structure of human parvovirus B19. Proc. Natl. Acad. Sci. USA 2004, 101, 11628-11633. [CrossRef]

5. Kailasan, S.; Halder, S.; Gurda, B.; Bladek, H.; Chipman, P.R.; McKenna, R.; Brown, K.; Agbandje-McKenna, M. Structure of an enteric pathogen, bovine parvovirus. J. Virol. 2015, 89, 2603-2614. [CrossRef] [PubMed]

6. Tsao, J.; Chapman, M.S.; Agbandje, M.; Keller, W.; Smith, K.; Wu, H.; Luo, M.; Smith, T.J.; Rossmann, M.G.; Compans, R.W.; et al. The three-dimensional structure of canine parvovirus and its functional implications. Science 1991, 251, 1456-1464. [CrossRef]

7. Simpson, A.A.; Chipman, P.R.; Baker, T.S.; Tijssen, P.; Rossmann, M.G. The structure of an insect parvovirus (Galleria mellonella densovirus) at 3.7 A resolution. Structure 1998, 6, 1355-1367. [CrossRef]

8. Meng, G.; Zhang, X.; Plevka, P.; Yu, Q.; Tijssen, P.; Rossmann, M.G. The structure and host entry of an invertebrate parvovirus. J. Virol. 2013, 87, 12523-12530. [CrossRef] [PubMed]

9. Kaufmann, B.; El-Far, M.; Plevka, P.; Bowman, V.D.; Li, Y.; Tijssen, P.; Rossmann, M.G. Structure of Bombyx mori densovirus 1, a silkworm pathogen. J. Virol. 2011, 85, 4691-4697. [CrossRef] [PubMed]

10. Zadori, Z.; Szelei, J.; Lacoste, M.C.; Li, Y.; Gariepy, S.; Raymond, P.; Allaire, M.; Nabi, I.R.; Tijssen, P. A viral phospholipase A2 is required for parvovirus infectivity. Dev. Cell 2001, 1, 291-302. [CrossRef]

11. Popa-Wagner, R.; Sonntag, F.; Schmidt, K.; King, J.; Kleinschmidt, J.A. Nuclear translocation of adeno-associated virus type 2 capsid proteins for virion assembly. J. Gen. Virol. 2012, 93, 1887-1898. [CrossRef]

12. Popa-Wagner, R.; Porwal, M.; Kann, M.; Reuss, M.; Weimer, M.; Florin, L.; Kleinschmidt, J.A. Impact of vp1-specific protein sequence motifs on adeno-associated virus type 2 intracellular trafficking and nuclear entry. J. Virol. 2012, 86, 9163-9174. [CrossRef] [PubMed]

13. Qu, X.W.; Liu, W.P.; Qi, Z.Y.; Duan, Z.J.; Zheng, L.S.; Kuang, Z.Z.; Zhang, W.J.; Hou, Y.D. Phospholipase A2-like activity of human bocavirus VP1 unique region. Biochem. Biophys. Res Commun. 2008, 365, 158-163. [CrossRef]

14. Buller, R.M.; Janik, J.E.; Sebring, E.D.; Rose, J.A. Herpes simplex virus types 1 and 2 completely help adenovirus-associated virus replication. J. Virol. 1981, 40, 241-247. [PubMed]

15. McPherson, R.A.; Rosenthal, L.J.; Rose, J.A. Human cytomegalovirus completely helps adeno-associated virus replication. Virology 1985, 147, 217-222. [CrossRef]

16. Weindler, F.W.; Heilbronn, R. A subset of herpes simplex virus replication genes provides helper functions for productive adeno-associated virus replication. J. Virol. 1991, 65, 2476-2483. [PubMed]

17. Chang, L.S.; Shi, Y.; Shenk, T. Adeno-associated virus P5 promoter contains an adenovirus E1A-inducible element and a binding site for the major late transcription factor. J. Virol. 1989, 63, 3479-3488.

18. Weitzman, M.D.; Linden, R.M. Adeno-associated virus biology. Methods Mol. Biol. 2011, 807, 1-23. [PubMed]

19. Laughlin, C.A.; Westphal, H.; Carter, B.J. Spliced adenovirus-associated virus rna. Proc. Natl. Acad. Sci. USA 1979, 76, 5567-5571. [CrossRef]

20. Qiu, J.; Soderlund-Venermo, M.; Young, N.S. Human parvoviruses. Clin. Microbiol. Rev. 2017, 30, 43-113.

21. Becerra, S.P.; Rose, J.A.; Hardy, M.; Baroudy, B.M.; Anderson, C.W. Direct mapping of adeno-associated virus capsid proteins b and c: A possible ACG initiation codon. Proc. Natl. Acad. Sci. USA 1985, 82, 7919-7923. [CrossRef] 
22. Becerra, S.P.; Koczot, F.; Fabisch, P.; Rose, J.A. Synthesis of adeno-associated virus structural proteins requires both alternative mrna splicing and alternative initiations from a single transcript. J. Virol. 1988, 62, 2745-2754.

23. Trempe, J.P.; Carter, B.J. Alternate mrna splicing is required for synthesis of adeno-associated virus Vp1 capsid protein. J. Virol. 1988, 62, 3356-3363. [PubMed]

24. Qiu, J.; Pintel, D. Processing of adeno-associated virus rna. Front. Biosci. 2008, 13, 3101-3115. [CrossRef] [PubMed]

25. Qiu, J.; Yoto, Y.; Tullis, G.E.; Pintel, D. Parvovirus RNA processing strategies. In Parvoviruses; Edward Arnold, Ltd.: London, UK, 2006; pp. 253-274.

26. Wistuba, A.; Kern, A.; Weger, S.; Grimm, D.; Kleinschmidt, J.A. Subcellular compartmentalization of adeno-associated virus type 2 assembly. J. Virol. 1997, 71, 1341-1352.

27. Cotmore, S.F.; D'Abramo, A.M., Jr.; Carbonell, L.F.; Bratton, J.; Tattersall, P. The NS2 polypeptide of parvovirus MVM is required for capsid assembly in murine cells. Virology 1997, 231, 267-280. [CrossRef] [PubMed]

28. Cotmore, S.F.; McKie, V.C.; Anderson, L.J.; Astell, C.R.; Tattersall, P. Identification of the major structural and nonstructural proteins encoded by human parvovirus B19 and mapping of their genes by procaryotic expression of isolated genomic fragments. J. Virol. 1986, 60, 548-557.

29. Buller, R.M.; Rose, J.A. Characterization of adenovirus-associated virus-induced polypeptides in KB cells. J. Virol. 1978, 25, 331-338. [PubMed]

30. Snijder, J.; van de Waterbeemd, M.; Damoc, E.; Denisov, E.; Grinfeld, D.; Bennett, A.; Agbandje-McKenna, M.; Makarov, A.; Heck, A.J. Defining the stoichiometry and cargo load of viral and bacterial nanoparticles by orbitrap mass spectrometry. J. Am. Chem. Soc. 2014, 136, 7295-7299. [CrossRef] [PubMed]

31. Rose, J.A.; Maizel, J.V., Jr.; Inman, J.K.; Shatkin, A.J. Structural proteins of adenovirus-associated viruses. J. Virol. 1971, 8, 766-770.

32. Sonntag, F.; Schmidt, K.; Kleinschmidt, J.A. A viral assembly factor promotes AAV2 capsid formation in the nucleolus. Proc. Natl. Acad. Sci. USA 2010, 107, 10220-10225. [CrossRef]

33. Bleker, S.; Pawlita, M.; Kleinschmidt, J.A. Impact of capsid conformation and rep-capsid interactions on adeno-associated virus type 2 genome packaging. J. Virol. 2006, 80, 810-820. [CrossRef]

34. Clinton, G.M.; Hayashi, M. The parovivirus MVM: Particles with altered structural proteins. Virology 1975, 66, 261-267. [CrossRef]

35. Weichert, W.S.; Parker, J.S.; Wahid, A.T.; Chang, S.F.; Meier, E.; Parrish, C.R. Assaying for structural variation in the parvovirus capsid and its role in infection. Virology 1998, 250, 106-117. [CrossRef] [PubMed]

36. Paradiso, P.R. Infectious process of the parvovirus h-1: Correlation of protein content, particle density, and viral infectivity. J. Virol. 1981, 39, 800-807. [PubMed]

37. Farr, G.A.; Cotmore, S.F.; Tattersall, P. Vp2 cleavage and the leucine ring at the base of the fivefold cylinder control ph-dependent externalization of both the $\mathrm{Vp} 1 \mathrm{~N}$ terminus and the genome of minute virus of mice. J. Virol. 2006, 80, 161-171. [CrossRef]

38. Wu, H.; Rossmann, M.G. The canine parvovirus empty capsid structure. J. Mol. Biol. 1993, 233, $231-244$. [CrossRef] [PubMed]

39. Ilyas, M.; Mietzsch, M.; Kailasan, S.; Vaisanen, E.; Luo, M.; Chipman, P.; Smith, J.K.; Kurian, J.; Sousa, D.; McKenna, R.; et al. Atomic resolution structures of human bufaviruses determined by Cryo-electron microscopy. Viruses 2018, 10, 22. [CrossRef]

40. Xie, Q.; Chapman, M.S. Canine parvovirus capsid structure, analyzed at 2.9 A resolution. J. Mol. Biol. 1996, 264, 497-520. [CrossRef]

41. Govindasamy, L.; Hueffer, K.; Parrish, C.R.; Agbandje-McKenna, M. Structures of host range-controlling regions of the capsids of canine and feline parvoviruses and mutants. J. Virol. 2003, 77, 12211-12221. [CrossRef]

42. Simpson, A.A.; Chandrasekar, V.; Hebert, B.; Sullivan, G.M.; Rossmann, M.G.; Parrish, C.R. Host range and variability of calcium binding by surface loops in the capsids of canine and feline parvoviruses. J. Mol. Biol. 2000, 300, 597-610. [CrossRef]

43. Llamas-Saiz, A.L.; Agbandje-McKenna, M.; Parker, J.S.; Wahid, A.T.; Parrish, C.R.; Rossmann, M.G. Structural analysis of a mutation in canine parvovirus which controls antigenicity and host range. Virology 1996, 225, 65-71. [CrossRef] [PubMed] 
44. Organtini, L.J.; Allison, A.B.; Lukk, T.; Parrish, C.R.; Hafenstein, S. Global displacement of canine parvovirus by a host-adapted variant: Structural comparison between pandemic viruses with distinct host ranges. J. Virol. 2015, 89, 1909-1912. [CrossRef] [PubMed]

45. Agbandje, M.; McKenna, R.; Rossmann, M.G.; Strassheim, M.L.; Parrish, C.R. Structure determination of feline Panleukopenia virus empty particles. Proteins 1993, 16, 155-171. [CrossRef] [PubMed]

46. Halder, S.; Nam, H.J.; Govindasamy, L.; Vogel, M.; Dinsart, C.; Salome, N.; McKenna, R.; Agbandje-McKenna, M. Structural characterization of H-1 parvovirus: Comparison of infectious virions to empty capsids. J. Virol. 2013, 87, 5128-5140. [CrossRef]

47. Pittman, N.; Misseldine, A.; Geilen, L.; Halder, S.; Smith, J.K.; Kurian, J.; Chipman, P.; Janssen, M.; McKenna, R.; Baker, T.S.; et al. Atomic resolution structure of the oncolytic parvovirus luiii by electron microscopy and $3 \mathrm{~d}$ image reconstruction. Viruses 2017, 9, 321. [CrossRef] [PubMed]

48. Callaway, H.M.; Subramanian, S.; Urbina, C.; Barnard, K.; Dick, R.; Bator, C.M.; Hafentein, S.L.; Gifford, R.J.; Parrish, C.R. Examination and reconstruction of three ancient endogenous parvovirus capsid protein gene remnants found in rodent genomes. J. Virol. 2019, 93, e01542-18. [CrossRef]

49. Llamas-Saiz, A.L.; Agbandje-McKenna, M.; Wikoff, W.R.; Bratton, J.; Tattersall, P.; Rossmann, M.G. Structure determination of minute virus of mice. Acta Crystallogr. Sect. D Biol. Crystallogr. 1997, 53, 93-102. [CrossRef]

50. Kontou, M.; Govindasamy, L.; Nam, H.J.; Bryant, N.; Llamas-Saiz, A.L.; Foces-Foces, C.; Hernando, E.; Rubio, M.P.; McKenna, R.; Almendral, J.M.; et al. Structural determinants of tissue tropism and in vivo pathogenicity for the parvovirus minute virus of mice. J. Virol. 2005, 79, 10931-10943. [CrossRef]

51. Plevka, P.; Hafenstein, S.; Li, L.; D’Abrgamo, A., Jr.; Cotmore, S.F.; Rossmann, M.G.; Tattersall, P. Structure of a packaging-defective mutant of minute virus of mice indicates that the genome is packaged via a pore at a 5-fold axis. J. Virol. 2011, 85, 4822-4827. [CrossRef]

52. Guerra, P.; Valbuena, A.; Querol-Audi, J.; Silva, C.; Castellanos, M.; Rodriguez-Huete, A.; Garriga, D.; Mateu, M.G.; Verdaguer, N. Structural basis for biologically relevant mechanical stiffening of a virus capsid by cavity-creating or spacefilling mutations. Sci. Rep. 2017, 7, 4101. [CrossRef] [PubMed]

53. Simpson, A.A.; Hebert, B.; Sullivan, G.M.; Parrish, C.R.; Zadori, Z.; Tijssen, P.; Rossmann, M.G. The structure of porcine parvovirus: Comparison with related viruses. J. Mol. Biol. 2002, 315, 1189-1198. [CrossRef] [PubMed]

54. Mietzsch, M.; Kailasan, S.; Garrison, J.; Ilyas, M.; Chipman, P.; Kantola, K.; Janssen, M.E.; Spear, J.; Sousa, D.; McKenna, R.; et al. Structural insights into human bocaparvoviruses. J. Virol. 2017, 91, e00261-17. [CrossRef] [PubMed]

55. Ng, R.; Govindasamy, L.; Gurda, B.L.; McKenna, R.; Kozyreva, O.G.; Samulski, R.J.; Parent, K.N.; Baker, T.S.; Agbandje-McKenna, M. Structural characterization of the dual glycan binding adeno-associated virus serotype 6. J. Virol. 2010, 84, 12945-12957. [CrossRef] [PubMed]

56. Drouin, L.M.; Lins, B.; Janssen, M.; Bennett, A.; Chipman, P.; McKenna, R.; Chen, W.; Muzyczka, N.; Cardone, G.; Baker, T.S.; et al. Cryo-electron microscopy reconstruction and stability studies of the wild type and the R432A variant of adeno-associated virus type 2 reveal that capsid structural stability is a major factor in genome packaging. J. Virol. 2016, 90, 8542-8551. [CrossRef]

57. Tan, Y.Z.; Aiyer, S.; Mietzsch, M.; Hull, J.A.; McKenna, R.; Grieger, J.; Samulski, R.J.; Baker, T.S.; Agbandje-McKenna, M.; Lyumkis, D. Sub-2 A Ewald curvature corrected structure of an AAV2 capsid variant. Nat. Commun. 2018, 9, 3628. [CrossRef] [PubMed]

58. Burg, M.; Rosebrough, C.; Drouin, L.M.; Bennett, A.; Mietzsch, M.; Chipman, P.; McKenna, R.; Sousa, D.; Potter, M.; Byrne, B.; et al. Atomic structure of a rationally engineered gene delivery vector, aav2.5. J. Struct. Biol. 2018, 203, 236-241. [CrossRef]

59. Lerch, T.F.; Xie, Q.; Chapman, M.S. The structure of adeno-associated virus serotype 3b (aav-3b): Insights into receptor binding and immune evasion. Virology 2010, 403, 26-36. [CrossRef]

60. Govindasamy, L.; Padron, E.; McKenna, R.; Muzyczka, N.; Kaludov, N.; Chiorini, J.A.; Agbandje-McKenna, M. Structurally mapping the diverse phenotype of adeno-associated virus serotype 4. J. Virol. 2006, 80, 11556-11570. [CrossRef]

61. Govindasamy, L.; Dimattia, M.A.; Gurda, B.L.; Halder, S.; McKenna, R.; Chiorini, J.A.; Muzyczka, N.; Zolotukhin, S.; Agbandje-McKenna, M. Structural insights into adeno-associated virus serotype 5. J. Virol. 2013, 87, 11187-11199. [CrossRef] 
62. Xie, Q.; Lerch, T.F.; Meyer, N.L.; Chapman, M.S. Structure-function analysis of receptor-binding in adeno-associated virus serotype 6 (AAV-6). Virology 2011, 420, 10-19. [CrossRef] [PubMed]

63. Nam, H.J.; Lane, M.D.; Padron, E.; Gurda, B.; McKenna, R.; Kohlbrenner, E.; Aslanidi, G.; Byrne, B.; Muzyczka, N.; Zolotukhin, S.; et al. Structure of adeno-associated virus serotype 8, a gene therapy vector. J. Virol. 2007, 81, 12260-12271. [CrossRef]

64. Nam, H.J.; Gurda, B.L.; McKenna, R.; Potter, M.; Byrne, B.; Salganik, M.; Muzyczka, N.; Agbandje-McKenna, M. Structural studies of adeno-associated virus serotype 8 capsid transitions associated with endosomal trafficking. J. Virol. 2011, 85, 11791-11799. [CrossRef] [PubMed]

65. DiMattia, M.A.; Nam, H.J.; Van Vliet, K.; Mitchell, M.; Bennett, A.; Gurda, B.L.; McKenna, R.; Olson, N.H.; Sinkovits, R.S.; Potter, M.; et al. Structural insight into the unique properties of adeno-associated virus serotype 9. J. Virol. 2012, 86, 6947-6958. [CrossRef]

66. Guenther, C.M.; Brun, M.J.; Bennett, A.D.; Ho, M.L.; Chen, W.; Zhu, B.; Lam, M.; Yamagami, M.; Kwon, S.; Bhattacharya, N.; et al. Protease-activatable adeno-associated virus vector for gene delivery to damaged heart tissue. Mol. Ther. 2019, 27, 611-622. [CrossRef] [PubMed]

67. Lerch, T.F.; O’Donnell, J.K.; Meyer, N.L.; Xie, Q.; Taylor, K.A.; Stagg, S.M.; Chapman, M.S. Structure of $\mathrm{AAV}-\mathrm{dj}$, a retargeted gene therapy vector: Cryo-electron microscopy at 4.5 A resolution. Structure 2012, 20, 1310-1320. [CrossRef] [PubMed]

68. Halder, S.; Van Vliet, K.; Smith, J.K.; Duong, T.T.; McKenna, R.; Wilson, J.M.; Agbandje-McKenna, M. Structure of neurotropic adeno-associated virus AAVrh.8. J. Struct. Biol. 2015, 192, 21-36. [CrossRef] [PubMed]

69. Mikals, K.; Nam, H.J.; Van Vliet, K.; Vandenberghe, L.H.; Mays, L.E.; McKenna, R.; Wilson, J.M.; Agbandje-McKenna, M. The structure of AAVrh32.33, a novel gene delivery vector. J. Struct. Biol. 2014, 186, 308-317. [CrossRef]

70. Kronenberg, S.; Bottcher, B.; von der Lieth, C.W.; Bleker, S.; Kleinschmidt, J.A. A conformational change in the adeno-associated virus type 2 capsid leads to the exposure of hidden Vp1 N termini. J. Virol. 2005, 79, 5296-5303. [CrossRef] [PubMed]

71. Kaufmann, B.; Chipman, P.R.; Kostyuchenko, V.A.; Modrow, S.; Rossmann, M.G. Visualization of the externalized Vp2 N termini of infectious human parvovirus B19. J. Virol. 2008, 82, 7306-7312. [CrossRef]

72. Xue, B.; Dunbrack, R.L.; Williams, R.W.; Dunker, A.K.; Uversky, V.N. Pondr-fit: A meta-predictor of intrinsically disordered amino acids. Biochim. Biophys. Acta 2010, 1804, 996-1010. [CrossRef] [PubMed]

73. Venkatakrishnan, B.; Yarbrough, J.; Domsic, J.; Bennett, A.; Bothner, B.; Kozyreva, O.G.; Samulski, R.J.; Muzyczka, N.; McKenna, R.; Agbandje-McKenna, M. Structure and dynamics of adeno-associated virus serotype 1 Vp1-unique n-terminal domain and its role in capsid trafficking. J. Virol. 2013, 87, 4974-4984. [CrossRef] [PubMed]

74. Agbandje-McKenna, M.; Kleinschmidt, J. Aav capsid structure and cell interactions. Methods Mol. Biol. 2011, 807, 47-92. [PubMed]

75. Bennett, A.; Mietzsch, M.; Agbandje-McKenna, M. Understanding capsid assembly and genome packaging for adeno-associated viruses. Future Virol. 2017, 12, 283-297. [CrossRef]

76. Chapman, M.S.; Agbandje-McKenna, M. Atomic structure of viral particles. In Parvoviruses; Bloom, M.E., Cotmore, S.F., Linden, R.M., Parrish, C.R., Kerr, J.R., Eds.; Edward Arnold, Ltd.: London, UK, 2006; pp. 109-123.

77. DeLano, W.L. The Pymol Molecular Graphics Syste; DeLano Scientific: San Carlos, CA, USA, 2002.

78. Pettersen, E.F.; Goddard, T.D.; Huang, C.C.; Couch, G.S.; Greenblatt, D.M.; Meng, E.C.; Ferrin, T.E. Ucsf chimera-A visualization system for exploratory research and analysis. J. Comput. Chem. 2004, 25, 1605-1612. [CrossRef]

79. Chapman, M.S.; Rossmann, M.G. Single-stranded DNA-protein interactions in canine parvovirus. Structure 1995, 3, 151-162. [CrossRef]

80. Grieger, J.C.; Johnson, J.S.; Gurda-Whitaker, B.; Agbandje-McKenna, M.; Samulski, R.J. Surface-exposed adeno-associated virus Vp1-NLS capsid fusion protein rescues infectivity of noninfectious wild-type Vp2/Vp3 and Vp3-only capsids but not that of fivefold pore mutant virions. J. Virol. 2007, 81, 7833-7843. [CrossRef] [PubMed]

81. Farr, G.A.; Tattersall, P. A conserved leucine that constricts the pore through the capsid fivefold cylinder plays a central role in parvoviral infection. Virology 2004, 323, 243-256. [CrossRef] [PubMed] 
82. Wu, P.; Xiao, W.; Conlon, T.; Hughes, J.; Agbandje-McKenna, M.; Ferkol, T.; Flotte, T.; Muzyczka, N. Mutational analysis of the adeno-associated virus type 2 (AAV2) capsid gene and construction of aav2 vectors with altered tropism. J. Virol. 2000, 74, 8635-8647. [CrossRef]

83. Hafenstein, S.; Palermo, L.M.; Kostyuchenko, V.A.; Xiao, C.; Morais, M.C.; Nelson, C.D.; Bowman, V.D.; Battisti, A.J.; Chipman, P.R.; Parrish, C.R.; et al. Asymmetric binding of transferrin receptor to parvovirus capsids. Proc. Natl. Acad. Sci. USA 2007, 104, 6585-6589. [CrossRef] [PubMed]

84. Hafenstein, S.; Bowman, V.D.; Sun, T.; Nelson, C.D.; Palermo, L.M.; Chipman, P.R.; Battisti, A.J.; Parrish, C.R.; Rossmann, M.G. Structural comparison of different antibodies interacting with parvovirus capsids. J. Virol. 2009, 83, 5556-5566. [CrossRef] [PubMed]

85. Hueffer, K.; Govindasamy, L.; Agbandje-McKenna, M.; Parrish, C.R. Combinations of two capsid regions controlling canine host range determine canine transferrin receptor binding by canine and feline parvoviruses. J. Virol. 2003, 77, 10099-10105. [CrossRef] [PubMed]

86. Huang, L.Y.; Halder, S.; Agbandje-McKenna, M. Parvovirus glycan interactions. Curr. Opin. Virol. 2014, 7, 108-118. [CrossRef] [PubMed]

87. Pillay, S.; Meyer, N.L.; Puschnik, A.S.; Davulcu, O.; Diep, J.; Ishikawa, Y.; Jae, L.T.; Wosen, J.E.; Nagamine, C.M.; Chapman, M.S.; et al. An essential receptor for adeno-associated virus infection. Nature 2016, 530, 108-112. [CrossRef] [PubMed]

88. Mietzsch, M.; Broecker, F.; Reinhardt, A.; Seeberger, P.H.; Heilbronn, R. Differential adeno-associated virus serotype-specific interaction patterns with synthetic heparins and other glycans. J. Virol. 2014, 88, 2991-3003. [CrossRef] [PubMed]

89. Akache, B.; Grimm, D.; Pandey, K.; Yant, S.R.; Xu, H.; Kay, M.A. The 37/67-kilodalton laminin receptor is a receptor for adeno-associated virus serotypes 8, 2, 3, and 9. J. Virol. 2006, 80, 9831-9836. [CrossRef]

90. Qing, K.; Mah, C.; Hansen, J.; Zhou, S.; Dwarki, V.; Srivastava, A. Human fibroblast growth factor receptor 1 is a co-receptor for infection by adeno-associated virus 2. Nat. Med. 1999, 5, 71-77. [CrossRef]

91. Kashiwakura, Y.; Tamayose, K.; Iwabuchi, K.; Hirai, Y.; Shimada, T.; Matsumoto, K.; Nakamura, T.; Watanabe, M.; Oshimi, K.; Daida, H. Hepatocyte growth factor receptor is a coreceptor for adeno-associated virus type 2 infection. J. Virol. 2005, 79, 609-614. [CrossRef] [PubMed]

92. Weller, M.L.; Amornphimoltham, P.; Schmidt, M.; Wilson, P.A.; Gutkind, J.S.; Chiorini, J.A. Epidermal growth factor receptor is a co-receptor for adeno-associated virus serotype 6. Nat. Med. 2010, 16, 662-664. [CrossRef] [PubMed]

93. Wu, Z.; Miller, E.; Agbandje-McKenna, M.; Samulski, R.J. Alpha2,3 and alpha2,6 n-linked sialic acids facilitate efficient binding and transduction by adeno-associated virus types 1 and 6. J. Virol. 2006, 80, 9093-9103. [CrossRef] [PubMed]

94. Di Pasquale, G.; Kaludov, N.; Agbandje-McKenna, M.; Chiorini, J.A. Baav transcytosis requires an interaction with Beta-1-4 linked- glucosamine and gp96. PLoS ONE 2010, 5, e9336. [CrossRef] [PubMed]

95. O'Donnell, J.; Taylor, K.A.; Chapman, M.S. Adeno-associated virus-2 and its primary cellular receptor-cryo-em structure of a heparin complex. Virology 2009, 385, 434-443. [CrossRef] [PubMed]

96. Levy, H.C.; Bowman, V.D.; Govindasamy, L.; McKenna, R.; Nash, K.; Warrington, K.; Chen, W.; Muzyczka, N.; Yan, X.; Baker, T.S.; et al. Heparin binding induces conformational changes in adeno-associated virus serotype 2. J. Struct. Biol. 2009, 165, 146-156. [CrossRef] [PubMed]

97. Xie, Q.; Spear, J.M.; Noble, A.J.; Sousa, D.R.; Meyer, N.L.; Davulcu, O.; Zhang, F.; Linhardt, R.J.; Stagg, S.M.; Chapman, M.S. The 2.8 A electron microscopy structure of adeno-associated virus-dj bound by a heparinoid pentasaccharide. Mol. Ther. Methods Clin. Dev. 2017, 5, 1-12. [CrossRef]

98. Afione, S.; DiMattia, M.A.; Halder, S.; Di Pasquale, G.; Agbandje-McKenna, M.; Chiorini, J.A. Identification and mutagenesis of the adeno-associated virus 5 sialic acid binding region. J. Virol. 2015, 89, 1660-1672. [CrossRef]

99. Lerch, T.F.; Chapman, M.S. Identification of the heparin binding site on adeno-associated virus serotype 3B (AAV-3B). Virology 2012, 423, 6-13. [CrossRef]

100. Huang, L.Y.; Patel, A.; Ng, R.; Miller, E.B.; Halder, S.; McKenna, R.; Asokan, A.; Agbandje-McKenna, M. Characterization of the adeno-associated virus 1 and 6 sialic acid binding site. J. Virol. 2016, 90, 5219-5230. [CrossRef] [PubMed] 
101. Lopez-Bueno, A.; Rubio, M.P.; Bryant, N.; McKenna, R.; Agbandje-McKenna, M.; Almendral, J.M. Host-selected amino acid changes at the sialic acid binding pocket of the parvovirus capsid modulate cell binding affinity and determine virulence. J. Virol. 2006, 80, 1563-1573. [CrossRef]

102. Zhang, R.; Cao, L.; Cui, M.; Sun, Z.; Hu, M.; Zhang, R.; Stuart, W.; Zhao, X.; Yang, Z.; Li, X.; et al. Adeno-associated virus 2 bound to its cellular receptor AAVR. Nat. Microbiol. 2019, 4, 675-682. [CrossRef]

103. Rohrer, C.; Gartner, B.; Sauerbrei, A.; Bohm, S.; Hottentrager, B.; Raab, U.; Thierfelder, W.; Wutzler, P.; Modrow, S. Seroprevalence of parvovirus B19 in the german population. Epidemiol. Infect. 2008, 136, 1564-1575. [CrossRef]

104. Boutin, S.; Monteilhet, V.; Veron, P.; Leborgne, C.; Benveniste, O.; Montus, M.F.; Masurier, C. Prevalence of serum igg and neutralizing factors against adeno-associated virus (AAV) types 1, 2, 5, 6, 8, and 9 in the healthy population: Implications for gene therapy using AAV vectors. Hum. Gene Ther. 2010, 21, 704-712. [CrossRef]

105. Guo, L.; Wang, Y.; Zhou, H.; Wu, C.; Song, J.; Li, J.; Paranhos-Baccala, G.; Vernet, G.; Wang, J.; Hung, T. Differential seroprevalence of human bocavirus species 1-4 in Beijing, China. PLoS ONE 2012, 7, e39644. [CrossRef] [PubMed]

106. Vaisanen, E.; Mohanraj, U.; Kinnunen, P.M.; Jokelainen, P.; Al-Hello, H.; Barakat, A.M.; Sadeghi, M.; Jalilian, F.A.; Majlesi, A.; Masika, M.; et al. Global distribution of human protoparvoviruses. Emerg. Infect. Dis. 2018, 24, 1292-1299. [CrossRef] [PubMed]

107. Sharp, C.P.; Vermeulen, M.; Nebie, Y.; Djoko, C.F.; LeBreton, M.; Tamoufe, U.; Rimoin, A.W.; Kayembe, P.K.; Carr, J.K.; Servant-Delmas, A.; et al. Changing epidemiology of human parvovirus 4 infection in sub-Saharan Africa. Emerg. Infect. Dis. 2010, 16, 1605-1607. [CrossRef]

108. Jose, A.; Mietzsch, M.; Smith, K.; Kurian, J.; Chipman, P.; McKenna, R.; Chiorini, J.; Agbandje-McKenna, M. High resolution structural characterization of a new aav 5 antibody epitope toward engineering antibody resistant recombinant gene delivery vectors. J. Virol. 2018, 93, e01394-18. [CrossRef]

109. von Kietzell, K.; Pozzuto, T.; Heilbronn, R.; Grossl, T.; Fechner, H.; Weger, S. Antibody-mediated enhancement of parvovirus B19 uptake into endothelial cells mediated by a receptor for complement factor C1Q. J. Virol. 2014, 88, 8102-8115. [CrossRef]

110. Kanno, H.; Wolfinbarger, J.B.; Bloom, M.E. Aleutian mink disease parvovirus infection of mink macrophages and human macrophage cell line u937: Demonstration of antibody-dependent enhancement of infection. J. Virol. 1993, 67, 7017-7024. [PubMed]

111. Organtini, L.J.; Lee, H.; Iketani, S.; Huang, K.; Ashley, R.E.; Makhov, A.M.; Conway, J.F.; Parrish, C.R.; Hafenstein, S. Near-atomic resolution structure of a highly neutralizing Fab bound to canine parvovirus. J. Virol. 2016, 90, 9733-9742. [CrossRef] [PubMed]

112. Kaufmann, B.; Lopez-Bueno, A.; Mateu, M.G.; Chipman, P.R.; Nelson, C.D.; Parrish, C.R.; Almendral, J.M.; Rossmann, M.G. Minute virus of mice, a parvovirus, in complex with the fab fragment of a neutralizing monoclonal antibody. J. Virol. 2007, 81, 9851-9858. [CrossRef]

113. Kailasan, S.; Garrison, J.; Ilyas, M.; Chipman, P.; McKenna, R.; Kantola, K.; Soderlund-Venermo, M.; Kucinskaite-Kodze, I.; Zvirbliene, A.; Agbandje-McKenna, M. Mapping antigenic epitopes on the human bocavirus capsid. J. Virol. 2016, 90, 4670-4680. [CrossRef]

114. Tseng, Y.S.; Gurda, B.L.; Chipman, P.; McKenna, R.; Afione, S.; Chiorini, J.A.; Muzyczka, N.; Olson, N.H.; Baker, T.S.; Kleinschmidt, J.; et al. Adeno-associated virus serotype 1 (AAV1)- and AAV5-antibody complex structures reveal evolutionary commonalities in parvovirus antigenic reactivity. J. Virol. 2015, 89, 1794-1808. [CrossRef] [PubMed]

115. Gurda, B.L.; DiMattia, M.A.; Miller, E.B.; Bennett, A.; McKenna, R.; Weichert, W.S.; Nelson, C.D.; Chen, W.J.; Muzyczka, N.; Olson, N.H.; et al. Capsid antibodies to different adeno-associated virus serotypes bind common regions. J. Virol. 2013, 87, 9111-9124. [CrossRef]

116. McCraw, D.M.; O’Donnell, J.K.; Taylor, K.A.; Stagg, S.M.; Chapman, M.S. Structure of adeno-associated virus-2 in complex with neutralizing monoclonal antibody A20. Virology 2012, 431, 40-49. [CrossRef] [PubMed]

117. Bennett, A.D.; Wong, K.; Lewis, J.; Tseng, Y.S.; Smith, J.K.; Chipman, P.; McKenna, R.; Samulski, R.J.; Kleinschmidt, J.; Agbandje-McKenna, M. AAV6 K531 serves a dual function in selective receptor and antibody ADK6 recognition. Virology 2018, 518, 369-376. [CrossRef] [PubMed] 
118. Gurda, B.L.; Raupp, C.; Popa-Wagner, R.; Naumer, M.; Olson, N.H.; Ng, R.; McKenna, R.; Baker, T.S.; Kleinschmidt, J.A.; Agbandje-McKenna, M. Mapping a neutralizing epitope onto the capsid of adeno-associated virus serotype 8. J. Virol. 2012, 86, 7739-7751. [CrossRef] [PubMed]

119. Giles, A.R.; Govindasamy, L.; Somanathan, S.; Wilson, J.M. Mapping an adeno-associated virus 9-specific neutralizing epitope to develop next-generation gene delivery vectors. J. Virol. 2018, 92. [CrossRef]

120. Sun, Y.; Klose, T.; Liu, Y.; Modrow, S.; Rossmann, M.G. Structure of parvovirus B19 decorated by Fabs from a human antibody. J. Virol. 2019. [CrossRef]

121. Daya, S.; Berns, K.I. Gene therapy using adeno-associated virus vectors. Clin. Microbiol. Rev. 2008, 21, 583-593. [CrossRef]

122. Fakhiri, J.; Schneider, M.A.; Puschhof, J.; Stanifer, M.; Schildgen, V.; Holderbach, S.; Voss, Y.; El Andari, J.; Schildgen, O.; Boulant, S.; et al. Novel chimeric gene therapy vectors based on adeno-associated virus (AAV) and four different mammalian bocaviruses (BOV). Mol. Ther. Methods Clin. Dev. 2019, 12, 202-222. [CrossRef]

123. Gray, J.T.; Zolotukhin, S. Design and construction of functional AAV vectors. Methods Mol. Biol. 2011, 807, 25-46. [PubMed]

124. Zhong, L.; Li, B.; Jayandharan, G.; Mah, C.S.; Govindasamy, L.; Agbandje-McKenna, M.; Herzog, R.W.; Weigel-Van Aken, K.A.; Hobbs, J.A.; Zolotukhin, S.; et al. Tyrosine-phosphorylation of AAV2 vectors and its consequences on viral intracellular trafficking and transgene expression. Virology 2008, 381, 194-202. [CrossRef] [PubMed]

125. Zhong, L.; Zhao, W.; Wu, J.; Li, B.; Zolotukhin, S.; Govindasamy, L.; Agbandje-McKenna, M.; Srivastava, A. A dual role of EGFR protein tyrosine kinase signaling in ubiquitination of AAV2 capsids and viral second-strand DNA synthesis. Mol. Ther. 2007, 15, 1323-1330. [CrossRef] [PubMed]

126. Zhong, L.; Li, B.; Mah, C.S.; Govindasamy, L.; Agbandje-McKenna, M.; Cooper, M.; Herzog, R.W.; Zolotukhin, I.; Warrington, K.H., Jr.; Weigel-Van Aken, K.A.; et al. Next generation of adeno-associated virus 2 vectors: Point mutations in tyrosines lead to high-efficiency transduction at lower doses. Proc. Natl. Acad. Sci. USA 2008, 105, 7827-7832. [CrossRef] [PubMed]

127. Aslanidi, G.V.; Rivers, A.E.; Ortiz, L.; Song, L.; Ling, C.; Govindasamy, L.; Van Vliet, K.; Tan, M.; Agbandje-McKenna, M.; Srivastava, A. Optimization of the capsid of recombinant adeno-associated virus 2 (AAV2) vectors: The final threshold? PLoS ONE 2013, 8, e59142. [CrossRef]

128. Gabriel, N.; Hareendran, S.; Sen, D.; Gadkari, R.A.; Sudha, G.; Selot, R.; Hussain, M.; Dhaksnamoorthy, R.; Samuel, R.; Srinivasan, N.; et al. Bioengineering of AAV2 capsid at specific serine, threonine, or lysine residues improves its transduction efficiency in vitro and in vivo. Hum. Gene Ther. Methods 2013, 24, 80-93. [CrossRef] [PubMed]

129. Hurlbut, G.D.; Ziegler, R.J.; Nietupski, J.B.; Foley, J.W.; Woodworth, L.A.; Meyers, E.; Bercury, S.D.; Pande, N.N.; Souza, D.W.; Bree, M.P.; et al. Preexisting immunity and low expression in primates highlight translational challenges for liver-directed AAV8-mediated gene therapy. Mol. Ther. 2010, 18, 1983-1994. [CrossRef]

130. Velazquez, V.M.; Meadows, A.S.; Pineda, R.J.; Camboni, M.; McCarty, D.M.; Fu, H. Effective depletion of pre-existing anti-aav antibodies requires broad immune targeting. Mol. Ther. Methods Clin. Dev. 2017, 4, 159-168. [CrossRef] [PubMed]

131. Mingozzi, F.; High, K.A. Immune responses to AAV vectors: Overcoming barriers to successful gene therapy. Blood 2013, 122, 23-36. [CrossRef] [PubMed]

132. Arruda, V.R.; Favaro, P.; Finn, J.D. Strategies to modulate immune responses: A new frontier for gene therapy. Mol. Ther. 2009, 17, 1492-1503. [CrossRef]

133. Wang, Z.; Storb, R.; Halbert, C.L.; Banks, G.B.; Butts, T.M.; Finn, E.E.; Allen, J.M.; Miller, A.D.; Chamberlain, J.S.; Tapscott, S.J. Successful regional delivery and long-term expression of a dystrophin gene in canine muscular dystrophy: A preclinical model for human therapies. Mol. Ther. 2012, 20, 1501-1507. [CrossRef]

134. Mingozzi, F.; Anguela, X.M.; Pavani, G.; Chen, Y.; Davidson, R.J.; Hui, D.J.; Yazicioglu, M.; Elkouby, L.; Hinderer, C.J.; Faella, A.; et al. Overcoming preexisting humoral immunity to aav using capsid decoys. Sci. Transl. Med. 2013, 5, 194ra192. [CrossRef] [PubMed]

135. Tse, L.V.; Klinc, K.A.; Madigan, V.J.; Castellanos Rivera, R.M.; Wells, L.F.; Havlik, L.P.; Smith, J.K.; Agbandje-McKenna, M.; Asokan, A. Structure-guided evolution of antigenically distinct adeno-associated virus variants for immune evasion. Proc. Natl. Acad. Sci. USA 2017, 114, E4812-E4821. [CrossRef] 
136. Tseng, Y.S.; Agbandje-McKenna, M. Mapping the aav capsid host antibody response toward the development of second generation gene delivery vectors. Front. Immunol. 2014, 5, 9. [CrossRef] [PubMed]

137. Buning, H.; Ried, M.U.; Perabo, L.; Gerner, F.M.; Huttner, N.A.; Enssle, J.; Hallek, M. Receptor targeting of adeno-associated virus vectors. Gene Ther. 2003, 10, 1142-1151. [CrossRef]

138. Yu, C.Y.; Yuan, Z.; Cao, Z.; Wang, B.; Qiao, C.; Li, J.; Xiao, X. A muscle-targeting peptide displayed on AAV2 improves muscle tropism on systemic delivery. Gene Ther. 2009, 16, 953-962. [CrossRef] [PubMed]

139. Dalkara, D.; Byrne, L.C.; Klimczak, R.R.; Visel, M.; Yin, L.; Merigan, W.H.; Flannery, J.G.; Schaffer, D.V. In vivo-directed evolution of a new adeno-associated virus for therapeutic outer retinal gene delivery from the vitreous. Sci. Transl. Med. 2013, 5, 189ra176. [CrossRef]

140. Judd, J.; Wei, F.; Nguyen, P.Q.; Tartaglia, L.J.; Agbandje-McKenna, M.; Silberg, J.J.; Suh, J. Random insertion of mcherry into vp3 domain of adeno-associated virus yields fluorescent capsids with no loss of infectivity. Mol. Ther. Nucleic Acids 2012, 1, e54. [CrossRef] [PubMed]

141. Asuri, P.; Bartel, M.A.; Vazin, T.; Jang, J.H.; Wong, T.B.; Schaffer, D.V. Directed evolution of adeno-associated virus for enhanced gene delivery and gene targeting in human pluripotent stem cells. Mol. Ther. 2012, 20, 329-338. [CrossRef]

142. Bowles, D.E.; McPhee, S.W.; Li, C.; Gray, S.J.; Samulski, J.J.; Camp, A.S.; Li, J.; Wang, B.; Monahan, P.E.; Rabinowitz, J.E.; et al. Phase 1 gene therapy for Duchenne muscular dystrophy using a translational optimized aav vector. Mol. Ther. 2012, 20,443-455. [CrossRef]

143. Bergoin, M.; Tijssen, P. Densoviruses: A highly diverse group of arthropod parvoviruses. In Insect Virology; Asgari, S., Johnson, K.N., Eds.; Horizon Scientific Press: Norfolk, UK, 2010; pp. 59-82.

144. Palinski, R.M.; Mitra, N.; Hause, B.M. Discovery of a novel parvovirinae virus, porcine parvovirus 7, by metagenomic sequencing of porcine rectal swabs. Virus Genes 2016, 52, 564-567. [CrossRef] [PubMed]

145. Baquerizo-Audiot, E.; Abd-Alla, A.; Jousset, F.X.; Cousserans, F.; Tijssen, P.; Bergoin, M. Structure and expression strategy of the genome of Culex pipiens densovirus, a mosquito densovirus with an ambisense organization. J. Virol. 2009, 83, 6863-6873. [CrossRef]

146. Tijssen, P.; Penzes, J.J.; Yu, Q.; Pham, H.T.; Bergoin, M. Diversity of small, single-stranded DNA viruses of invertebrates and their chaotic evolutionary past. J. Invertebr. Pathol. 2016, 140, 83-96. [CrossRef]

147. Kim, E.; Magen, A.; Ast, G. Different levels of alternative splicing among eukaryotes. Nucleic Acids Res. 2007, 35, 125-131. [CrossRef] [PubMed]

148. Roediger, B.; Lee, Q.; Tikoo, S.; Cobbin, J.C.A.; Henderson, J.M.; Jormakka, M.; O’Rourke, M.B.; Padula, M.P.; Pinello, N.; Henry, M.; et al. An atypical parvovirus drives chronic tubulointerstitial nephropathy and kidney fibrosis. Cell 2018, 175, 530-543.e524. [CrossRef] [PubMed]

149. Tijssen, P.; Li, Y.; El-Far, M.; Szelei, J.; Letarte, M.; Zadori, Z. Organization and expression strategy of the ambisense genome of densonucleosis virus of Galleria mellonella. J. Virol. 2003, 77, 10357-10365. [CrossRef]

150. Yang, B.; Dong, X.; Cai, D.; Wang, X.; Liu, Z.; Hu, Z.; Wang, H.; Cao, X.; Zhang, J.; Hu, Y. Characterization of the promoter elements and transcription profile of Periplaneta fuliginosa densovirus nonstructural genes. Virus Res. 2008, 133, 149-156. [CrossRef]

151. Liu, K.; Li, Y.; Jousset, F.X.; Zadori, Z.; Szelei, J.; Yu, Q.; Pham, H.T.; Lepine, F.; Bergoin, M.; Tijssen, P. The Acheta domesticus densovirus, isolated from the european house cricket, has evolved an expression strategy unique among parvoviruses. J. Virol. 2011, 85, 10069-10078. [CrossRef] [PubMed]

152. Yu, Q.; Tijssen, P. Gene expression of five different iteradensoviruses: Bombyx mori densovirus, Casphalia extranea densovirus, Papilio polyxenes densovirus, Sibine fusca densovirus, and Danaus plexippus densovirus. J. Virol. 2014, 88, 12152-12157. [CrossRef] [PubMed]

153. Li, Y.; Zadori, Z.; Bando, H.; Dubuc, R.; Fediere, G.; Szelei, J.; Tijssen, P. Genome organization of the densovirus from Bombyx mori (BmDNV-1) and enzyme activity of its capsid. J. Gen. Virol. 2001, 82, 2821-2825. [CrossRef]

154. Pham, H.T.; Jousset, F.X.; Perreault, J.; Shike, H.; Szelei, J.; Bergoin, M.; Tijssen, P. Expression strategy of Aedes albopictus densovirus. J. Virol. 2013, 87, 9928-9932. [CrossRef] [PubMed]

155. Pham, H.T. Molecular Biology of Single-Stranded DNA Viruses in Shrimps and Crickets. Ph.D. Thesis, Université du Québec, Quebec City, QC, Canada, 2015.

156. Sukhumsirichart, W.; Attasart, P.; Boonsaeng, V.; Panyim, S. Complete nucleotide sequence and genomic organization of hepatopancreatic parvovirus (HPV) of penaeus monodon. Virology 2006, 346, 266-277. [CrossRef] 
157. Kaufmann, B.; Bowman, V.D.; Li, Y.; Szelei, J.; Waddell, P.J.; Tijssen, P.; Rossmann, M.G. Structure of Penaeus stylirostris densovirus, a shrimp pathogen. J. Virol. 2010, 84, 11289-11296. [CrossRef]

158. Bruemmer, A.; Scholari, F.; Lopez-Ferber, M.; Conway, J.F.; Hewat, E.A. Structure of an insect parvovirus (Junonia coenia Densovirus) determined by cryo-electron microscopy. J. Mol. Biol. 2005, 347, 791-801. [CrossRef]

159. Chen, S.; Cheng, L.; Zhang, Q.; Lin, W.; Lu, X.; Brannan, J.; Zhou, Z.H.; Zhang, J. Genetic, biochemical, and structural characterization of a new densovirus isolated from a chronically infected aedes albopictus C6/36 cell line. Virology 2004, 318, 123-133. [CrossRef]

160. Holm, L.; Rosenstrom, P. Dali server: Conservation mapping in 3d. Nucleic Acids Res. 2010, 38, W545-W549. [CrossRef]

161. Harrison, S.C.; Olson, A.J.; Schutt, C.E.; Winkler, F.K.; Bricogne, G. Tomato bushy stunt virus at 2.9 a resolution. Nature 1978, 276, 368-373. [CrossRef] [PubMed]

162. Rossmann, M.G.; Abad-Zapatero, C.; Hermodson, M.A.; Erickson, J.W. Subunit interactions in southern bean mosaic virus. J. Mol. Biol. 1983, 166, 37-73. [CrossRef]

163. Multeau, C.; Froissart, R.; Perrin, A.; Castelli, I.; Casartelli, M.; Ogliastro, M. Four amino acids of an insect Densovirus capsid determine midgut tropism and virulence. J. Virol. 2012, 86, 5937-5941. [CrossRef] [PubMed]

164. Wang, Y.; Gosselin Grenet, A.S.; Castelli, I.; Cermenati, G.; Ravallec, M.; Fiandra, L.; Debaisieux, S.; Multeau, C.; Lautredou, N.; Dupressoir, T.; et al. Densovirus crosses the insect midgut by transcytosis and disturbs the epithelial barrier function. J. Virol. 2013, 87, 12380-12391. [CrossRef] [PubMed]

165. Kozlov, E.N.; Martynova, E.U.; Popenko, V.I.; Schal, C.; Mukha, D.V. Intracellular localization of blattella germanica Densovirus (BgDV1) capsid proteins. Viruses 2018, 10, 370. [CrossRef]

166. Owens, L. Bioinformatical analysis of nuclear localisation sequences in penaeid densoviruses. Mar. Genomics 2013, 12, 9-15. [CrossRef] [PubMed]

167. Xu, P.; Yuan, H.; Yang, X.; Graham, R.I.; Liu, K.; Wu, K. Structural proteins of helicoverpa armigera Densovirus 2 enhance transcription of viral genes through transactivation. Arch. Virol. 2017, 162, 1745-1750. [CrossRef] [PubMed]

168. Aydemir, F.; Salganik, M.; Resztak, J.; Singh, J.; Bennett, A.; Agbandje-McKenna, M.; Muzyczka, N. Mutants at the 2-fold interface of adeno-associated virus type 2 (AAV2) structural proteins suggest a role in viral transcription for aav capsids. J. Virol. 2016, 90, 7196-7204. [CrossRef] [PubMed]

169. McKenna, R.; Olson, N.H.; Chipman, P.R.; Baker, T.S.; Booth, T.F.; Christensen, J.; Aasted, B.; Fox, J.M.; Bloom, M.E.; Wolfinbarger, J.B.; et al. Three-dimensional structure of aleutian mink disease parvovirus: Implications for disease pathogenicity. J. Virol. 1999, 73, 6882-6891. 